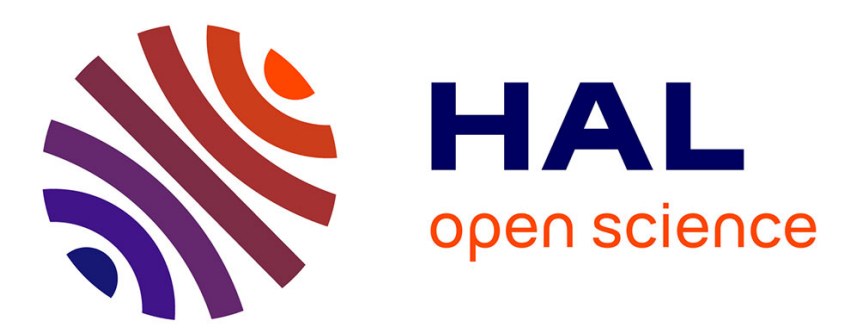

\title{
The effect of doum palm fibers on the mechanical and thermal properties of gypsum mortar
}

Fatma Naiiri, Lamis Allègue, Mehdi Salem, Redouane Zitoune, Mondher Zidi

\section{To cite this version:}

Fatma Naiiri, Lamis Allègue, Mehdi Salem, Redouane Zitoune, Mondher Zidi. The effect of doum palm fibers on the mechanical and thermal properties of gypsum mortar. Journal of Composite Materials, 2019, 53 (19), pp.2641-2659. 10.1177/0021998319838319 . hal-02134405

\section{HAL Id: hal-02134405 \\ https://hal.science/hal-02134405}

Submitted on 9 Nov 2020

HAL is a multi-disciplinary open access archive for the deposit and dissemination of scientific research documents, whether they are published or not. The documents may come from teaching and research institutions in France or abroad, or from public or private research centers.
L'archive ouverte pluridisciplinaire HAL, est destinée au dépôt et à la diffusion de documents scientifiques de niveau recherche, publiés ou non, émanant des établissements d'enseignement et de recherche français ou étrangers, des laboratoires publics ou privés. 


\title{
The effect of doum palm fibers on the mechanical and thermal properties of gypsum mortar
}

\author{
Naiiri Fatma' ${ }^{\circ}$, Lamis Allègue', Mehdi Salem², \\ Redouane Zitoune ${ }^{2}$ and Mondher Zidi'
}

\begin{abstract}
The main objective of this paper is the evaluation of the possibility of using a gypsum mortar reinforced with doum palm fibers as thermal insulators in building material. Several composite configurations with three sizes and five-weight ratios (from $0.5 \%$ to $2.5 \%$ ) of doum palm fiber were prepared for mechanical and thermo-physical characterization. Generally, natural fibers are affected by the alkali environment of gypsum mortar. To overcome this problem, doum palm fibers were treated with a $\mathrm{NaOH}$ solution of $1 \%$ concentration to enhance their resistance against chemical degradation. Chemical treatment of fiber removes some hemicellulose and lignin and tends to make the fiber more homogenous, which enhances fiber-matrix interfacial properties. In addition, the mechanical properties of the specimens were tested after 7 days, 28 days and I year of curing in normal conditions. The obtained results show an improvement in the mechanical performance of composites reinforced with treated fibers. In fact, better results were obtained for gypsum mortar reinforced with treated reinforcement seive2 for the value of $1 \%$ of fibers. It was also noticed that $\mathrm{NaOH}$ treatment has an influence on the thermal conductivities. In fact, the use of treated doum palm fibers as reinforcement in gypsum mortar seems to be an alternative natural material to be used as a thermal insulator material.
\end{abstract}

\section{Keywords}

Gypsum mortar, doum palm fiber, building material, alkali treatment, mechanical test, thermo-physical test

\section{Introduction}

Gypsum is commonly used as a building material due to its diverse advantage, including important fire resistant, sound and thermal isolation properties, lower cost and lower consumption energy. ${ }^{1,2}$ Moreover, gypsum can be recycled for several times using an appropriate process. $^{2}$ Accordingly, gypsum presents renowned issues as mentioned by some researchers in recent decades. ${ }^{3}$ Among these problems, we can mention the brittle behavior of gypsum against flexion which restricts their use under some special condition. ${ }^{4-6}$ To overcome this problem, the addition of fibers such as glass fibers and polypropylene fibers was used in order to enhance the flexural strength, fracture energy and toughness of the gypsum mortar composites. ${ }^{6,7}$ In addition, over the last few years, in order to reduce cost and to minimize environmental impact of production, researchers have focused on the possibility to replace the synthetic fibers with natural ones as reinforcement used in gypsum composites. ${ }^{5}$
Natural fibers are a renewable resource substantially available in numerous countries. Their mechanical and thermal properties, however, are not well known and a lot of variability in the mechanical properties of these materials has been observed. ${ }^{7,8}$

Natural fibers are essentially composed of cellulose, hemicellulose, and lignin. They have a variation in their properties according to the age of the plant and growing condition..$^{9,10}$ Their important tensile strength is a

\footnotetext{
'Laboratory of Mechanical Engineering, National School of Engineering of Monastir, University of Monastir, Tunisia

${ }^{2}$ Institut Clément Ader (ICA), CNRS UMR 53I2, France
}

\section{Corresponding author:}

Naiiri Fatma, Laboratory of Mechanical Engineering, University of Monastir, National School of Engineering of Monastir 5000,Tunisia Institut Clément Ader (ICA), CNRS UMR 53 I2, I33c, av. de Rangueil, Toulouse Cedex 31077, France.

Email: fatma.naiiri@gmail.com 
principal item in increasing the fracture toughness and improving the brittle behavior of gypsum. ${ }^{11,12}$

Lately, many studies have looked to evaluate the influence of adding natural fiber in the gypsum matrix, especially on the matter of mechanical properties of gypsum composite. ${ }^{13,14}$ One of the primary disadvantages of using natural fiber as reinforcement in building materials is the poor interaction between fiber and concrete. Accordingly, numerous studies focused on chemical (alkali treatment, silane treatment, andacelytic treatment) and physical treatment of the fiber to improve the fiber matrix adhesion by improving their surface. ${ }^{11,12}$ Treated fiber has lower diameter and densities because treatment removes impurities and amorphous components from surface. Moreover, treated fiber has better mechanical properties, and they show an increase of stress by $70 \% .^{12}$

Given that natural fibers have cellular porous structures, they contain a high content of hydroxyl groups $(-\mathrm{OH})$ which is considered as responsible for their degradation. Fibers are treated to resist the alkali attack sequels and hence to increase their strength and toughness. ${ }^{14,15}$ The great capacity of natural fibers to absorb water beside the alkaline attack by the matrix leads to the reduction of its performance. ${ }^{14}$

This behavior can be mastered through alkali treatment in order to clean the surface of fibers. The obtained result has been reported by several researchers ${ }^{15,16}$ asserting a considerable enhancement in the interfacial adhesion between fibers and matrix after alkali treatment.

Several approaches study the influence of the length of the fiber on the mechanical properties of the composites. In this context, Benmansour et al. ${ }^{16}$ found out that the use of long date palm fiber gives a better result of flexural strength than short fibers. As a matter of fact, mechanical properties were experimentally investigated to evaluate the effect of introducing different length and volume content of jute yarn as concrete reinforcement. ${ }^{17}$ In the work conducted by Monties, ${ }^{17}$ it was found that the maximum increment of compressive flexural and tensile strength is obtained for $15 \mathrm{~mm}$ and $0.1 \%$ volume fraction.

Indeed, natural fibers are used in different types of materials to enhance their mechanical properties, but to minimize energy consumption they should also have good thermo-physical properties. The fiber content of composite affects thermal conductivity which decreases with the increase of fiber quantities. From the measured value, it was $0.30 \mathrm{Wm}^{-1} \mathrm{k}^{-1}$ and by adding fiber it comes to be $0.21 \mathrm{~W} \mathrm{~m}^{-1} \mathrm{k}^{-1}$. ${ }^{18}$

Increasing the fiber content makes the composite more isolated, and thermal diffusivity decreases by $55.9 \%$, $44.4 \%$ and $33.2 \%$ for composite reinforced with barley straw, wheat straw and wood straw, respectively. ${ }^{19}$
Palumbo et al. $^{20}$ studied the thermal diffusivity and conductivity of plaster reinforced with three types of vegetable fibers such as corn, pith, and barley. The obtained results have shown that thermal conductivity was decreased by including the vegetable fibers due to the reduction of density. In addition, the most important reduction of thermal conductivity was obtained with specimens reinforced by the corn pith. More recently, other authors have investigated the effect of density on thermal conductivity of natural plaster reinforced with a different type of fiber notably wood shaving, barley straw, and wheat straw. ${ }^{18}$ The obtained results clearly show that the lower values of thermal conductivity were measured on specimens reinforced with wood shaving. ${ }^{19}$

Actually, hemp fibers are quite employed for sustainable construction material. ${ }^{21-23}$ In this context, Mazhoud et al. ${ }^{24}$ have evaluated the thermal properties of line plaster reinforced with different sizes of hemp fiber. Results showed that better interest findings are obtained for composites reinforced with the smallest hemp shiv. Similar results have been obtained by Asasutjarit et al. ${ }^{21}$ and Djoudi et al. ${ }^{22}$ In fact, it was mentioned that the fibers size affects the thermal conductivity and for a given fiber content, composites reinforced with short fibers have a lower thermal conductivity than composite reinforced with long fiber. ${ }^{23}$ Indeed, various attempts have been made that declared that the percentage of the addition was quite low than $10 \mathrm{wt} . \%$ compared to composite reinforced with natural fiber. ${ }^{25}$

Despite the various researches on the mechanical and thermal characteristic of natural fiber as reinforcement of gypsum-based composite, their durability in different aging conditions is still underestimated. Thus, it is essential to take the durability of this material into consideration in order to respond to the safety criteria. ${ }^{26}$

Politécnica et al. ${ }^{27}$ evaluated the effect of three years' natural aging on the durability of gypsum mortar reinforced with coir fiber used to produce wall panels. They concluded that the bending strength of the specimens was reduced by $16.66 \%$ during six months of aging, . Indeed, for three years, the performance of composite had not been reduced.

Accelerated aging conditions are a developing technology used in the laboratory to simulate the durability of composite exposed to varying environmental conditions. ${ }^{28,29}$ Belayachi et al. ${ }^{30}$ found that barley-straw loses its performance under long-term condition.

If we refer to the literature works, most are focused on palm fiber that is usually used to reinforce cement, ${ }^{31}$ concrete $^{32}$ and gypsum matrix ${ }^{23}$ However, the effects of adding doum palm fiber have never been discussed, despite every year, an important quantities of old leaves was removed and dropped. 
For these reasons, our objective is to discuss the eventual benefits of mechanical and thermo-physical properties of gypsum mortar by adding these plentiful fibers. More specially, the aim is to evaluate the effects of doum palm fibers on mechanical and thermo-physical properties of gypsum mortar. In addition, the impact of optimum size and percentages of added fibers in the formulation of gypsum mortar is investigated.

\section{Materials}

\section{Presentation of doum palm fiber}

The used doum palm tree belongs to the palm tree family of Arecaceae. It can grow up to $17 \mathrm{~m}$ high and the trunk can have a girth of up to $90 \mathrm{~cm}$. This tree is

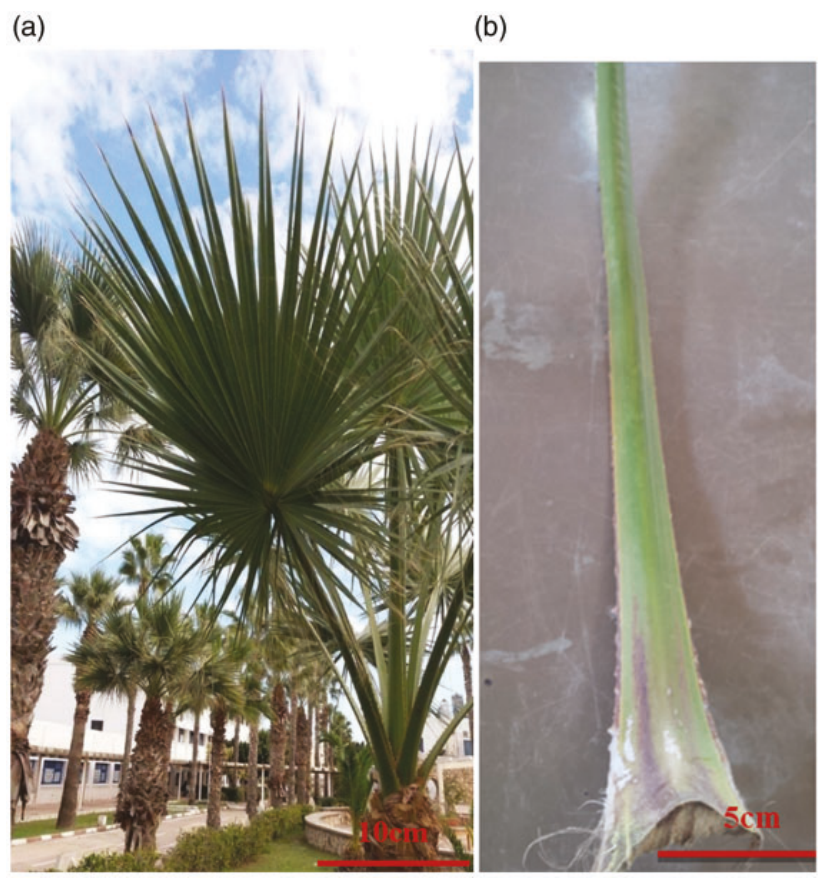

Figure I. Doum palm.With: (a) palm tree,(b) palm petiole. normally found in the northern half of Africa and is used as a decorative plant in rural and urban areas. ${ }^{31}$ Annually, the old and the big leaves are removed from the tree and thrown. Therefore, to minimize the waste of this natural and renewable material, we opted for using the fibers extracted from these leaves as gypsum mortar reinforcement.

\section{Fiber extraction}

The leaf of the doum palm fiber is composed of petiole on which the leaflets grow. In this study, we used the petiole of doum palm fiber. The natural fibers used in this work are extracted from a doum palm petiole harvested from Monastir (Figure 1).

The extraction process consists of several steps. The first one consists in peeling out the leafstalks by a knife. These leafstalks are subsequently crushed using a grinder made in a mechanical engineering laboratory of the national engineering school of Monastir.

From this method of extraction, a mixture of different lengths of fibers was obtained. To study the effects of the fibers lengths on the mechanical and thermal properties of gypsum mortar, the fibers were screened using different meshes of the grid. For this reason, three types of fiber sizes are manufactured and presented in Figure 2 and listed below:

- Reinforcement sieve1 with $0.1 \mathrm{~mm}$ mesh noted (RS1).

- Reinforcement sieve2 with $0.2 \mathrm{~mm}$ mesh (RS2).

- Reinforcement sieve3 with $0.3 \mathrm{~mm}$ mesh (RS3).

\section{Fiber treatment}

The main objective of the chemical treatment is to eliminate the weak boundary layers of natural fibers such as lignin and hemicellulose which have no resistance to the alkali environment of the gypsum.

The alkaline treatment disrupts more the hydrogen bonding in the network structure and adds an aqueous sodium hydroxide $(\mathrm{NaOH})$ to natural fibers. (a)

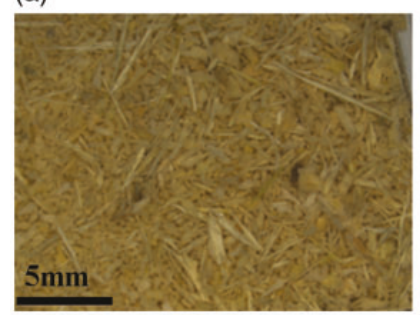

(b)

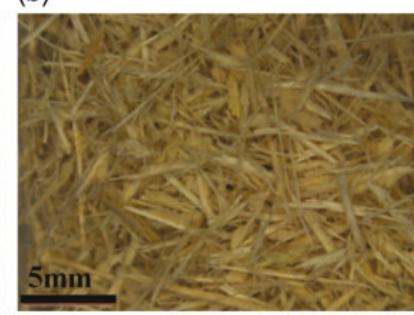

(c)

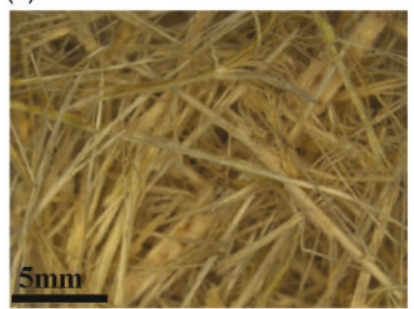

Figure 2. Pictures showing the three kinds of doum palm fibers. With: (a) Fibers referenced under RSI, (b): fibers referenced under RS2 and (c): fibers referenced under RS3. 
This favors the ionization of the hydroxyl group and increases the surface roughness (equation (1)) ${ }^{33}$

$$
\text { Fiber }-\mathrm{OH}-\mathrm{NaOH} \rightarrow \text { Fiber }-\mathrm{o}^{-} \mathrm{Na}^{+}+\mathrm{H}_{2} \mathrm{O}
$$

Many researchers have proved that the time of immersing and the chemical solution concentration used for treatment can affect the properties of this fiber. ${ }^{30-31}$ For this reason, we used the method recommended by Zbidi et al. ${ }^{16,30}$ This method consists in immersing the doum palm fibers into a $1 \%$ concentration of $\mathrm{NaOH}$ solution at a temperature of $105^{\circ} \mathrm{C}$ for $1 \mathrm{~h}$. The fibers were thoroughly rinsed with distilled water to remove any excess of $\mathrm{NaOH}$ solution sticking to the surface of the fiber. Then, they were bleached with sodium chloride and finally washed again with distilled water.

\section{Sand}

Rolled sand with granulomere $(0 / 2)$ was used in the experiments. The physical properties of used sand are presented in Table 1.

\section{Lime}

As a retardant of plaster setting time, an aerial lime with $6 \%$ mass fraction was used. Her addition to the mixture does not affect the mechanical properties of the mixture but it increases the time of employment of mixture by decreasing their solubility.

Table I. Sand physical properties.

\begin{tabular}{llll}
\hline $\begin{array}{l}\text { MF } \\
\text { fineness } \\
\text { modulus }\end{array}$ & $\begin{array}{l}\text { Apparent } \\
\text { volumic } \\
\text { mass }\left(\mathrm{kg} / \mathrm{m}^{3}\right)\end{array}$ & $\begin{array}{l}\text { The equivalent } \\
\text { of sand to the } \\
\text { piston ESP\% }\end{array}$ & $\begin{array}{l}\text { The equivalent } \\
\text { of sand visual } \\
\text { ESV (\%) }\end{array}$ \\
\hline 2.315 & 1470 & 71.91 & 78.56 \\
\hline
\end{tabular}

Table 2. Plaster particle size analysis.

\begin{tabular}{lllll}
\hline Size $(\mu \mathrm{m})$ & 250 & 180 & 90 & 63 \\
\hline Finer $(\%)$ & $\leq 0.2$ & $1-2.5$ & $12-17$ & $22-28$ \\
\hline
\end{tabular}

\section{Plaster}

The gypsum used in this study was produced by heating between $150^{\circ} \mathrm{C}$ and $170^{\circ} \mathrm{C}$ of the natural gypsum from the south of Tunisia (Tataouine) according to the reaction (equation (2))

$$
\mathrm{CaSO}_{4} \cdot 2 \mathrm{H}_{2} \mathrm{O} \rightarrow \mathrm{CaSO}_{4} 0.5 \mathrm{H}_{2} \mathrm{O}+1.5 \mathrm{H}_{2} \mathrm{O}
$$

The technical feature of the gypsum according to the standard NT $47-23$, EN $13279-2^{34}$ is presented in Tables 2 and 3.

\section{Composite preparation}

The prepared composites are made from gypsum conforming to European standard NF EN 13279-1, ${ }^{35}$ natural quartz sand $0 / 2 \mathrm{~mm}$ and doum palm fibers. To extend the setting time of plaster, an aerial lime was used. The composites are obtained by mixing all the components cited above for several weight percentages of doum palm fiber from $0.5 \%$ to $2.5 \%$ with a step of $0.5 \%$ weight fraction.

The same composition was used for the reference mortar and the reinforced gypsum mortar. We take the following composition according to the work of Mokhtar. ${ }^{36}$

- The report $\frac{W}{P+S}=0.6$

- The report $\frac{S}{P}=0.5$

- We added $6 \%$ of aerial lime as a retarding of setting time.

We designed by W: water; S: sand and P: plaster.

A mortar mixer with a maximum capacity of 51 was used to produce the gypsum mortar. The composites were produced using the following procedure:

1. The sand and the fibers were initially mixed in dry.

2. The plaster was added and mixed with the fibers and sand.

3. Finally, tap water and aerial lime were added and mixed for $2.5 \mathrm{~mm}$.

After the mixing, the half volumes of molds are filled with gypsum mortar and were shacked using a shaking table for $30 \mathrm{~s}$. After that the molds were completely filled and shaken for another $30 \mathrm{~s}$ to ensure a good

Table 3. Characteristics of gypsum.

\begin{tabular}{lllll}
\hline $\begin{array}{l}\text { Final setting } \\
\text { time }(\mathrm{min})\end{array}$ & $\begin{array}{l}\text { Porosity } \\
(\%)\end{array}$ & $\begin{array}{l}\text { Compressive } \\
\text { strength }(\mathrm{MPa})\end{array}$ & $\begin{array}{l}\text { Flexural } \\
\text { strength }(\mathrm{MPa})\end{array}$ & $\begin{array}{l}\text { Capillary water } \\
\text { absorption }(\%)\end{array}$ \\
\hline 19 & 41 & 9.3 & 5.1 & 39 \\
\hline
\end{tabular}


Table 4. Mix proportion of the gypsum mortar $\left(\mathrm{kg} / \mathrm{m}^{3}\right)$.

\begin{tabular}{llcccc}
\hline $\begin{array}{l}\text { Fiber } \\
\text { ratio (\%) }\end{array}$ & Gypsum & Sand & water & Lime & Fibers \\
\hline 0 & 1141.9 & 571.6 & 1028.6 & 164.06 & 0 \\
0.5 & 1141.9 & 571.6 & 1028.6 & 164.06 & 14.32 \\
1 & 1141.9 & 571.6 & 1028.6 & 164.06 & 28.64 \\
1.5 & 1141.9 & 571.6 & 1028.6 & 164.06 & 42.96 \\
2 & 1141.9 & 571.6 & 1028.6 & 164.06 & 57.28 \\
2.5 & 1141.9 & 571.6 & 1028.6 & 164.06 & 71.6 \\
\hline
\end{tabular}

Table 5. Gypsum mortar component.

\begin{tabular}{ll}
\hline Mix type & Designation \\
\hline RGM & Reference gypsum mortar \\
SNTI & Gypsum mortar + untreated fiber sieve I \\
SNT2 & Gypsum mortar + untreated fiber sieve 2 \\
SNT3 & Gypsum mortar + untreated fiber sieve 3 \\
STI & Gypsum mortar + treated fiber sieve I \\
ST2 & Gypsum mortar + treated fiber sieve 2 \\
ST3 & Gypsum mortar + treated fiber sieve 3 \\
\hline
\end{tabular}

distribution and a proper orientation of the fiber. The specimens were unmolded after $24 \mathrm{~h}$ and they were cured under laboratory conditions during 28 days. Each experimental test was repeated three times.

The details of the mix proportions per cubic meter for all composites are presented in Table 4.

The designations of the various gypsum mortars are presented in Table 5.

\section{Experimental methods}

\section{Fibers characterization}

\section{Physical properties}

Fiber diameter. The fiber diameter was measured using the projector profile machine. An average of 100 holds section was measured for the various fibers.

Linear density. The measurement of the linear density of doum palm fiber was carried out on the normal atmosphere of relative humidity of $65 \% \pm 2 \%$ and ambient temperature of $20^{\circ} \mathrm{C} \pm 2^{\circ} \mathrm{C}$ according to the French Standard NF G 07-004. ${ }^{37}$

Moisture content. Moisture content is the weight of water in the fiber as a percentage of the total weight of the material. A BRANCA Ideal air instrument was used to measure the moisture content of doum palm fiber. The purpose of the method is to determine the moisture content under prevailing conditions. The oven is fixed at a temperature $105 \pm 2^{\circ} \mathrm{C}$ and a sample mass of $100 \mathrm{~g}$ is required.

FTIR spectroscopy. The FTIR spectroscopy test was performed to examine the influence of the treatments on the chemical composition of the fibers and to correlate that with their impact on the mortar behavior. The apparatus used is a CARY 630 FTIR - crystal Diamond ATR; 32 scans were required at a resolution of $2 \mathrm{~cm}^{-1}$ with a scanning range between $4000 \mathrm{~cm}^{-1}$ and $650 \mathrm{~cm}^{-1}$.

Mechanical properties. The mechanical properties of doum palm fiber (tensile test, elongation and the modulus of elasticity) were performed using an LLYOD dynamometer with a load cell of $100 \mathrm{~N}$ according to standard ISO 5079. ${ }^{38}$ The tensile strength of treated and raw fibers was calculated as the average of 20 fibers with the effective length of measurement being $20 \mathrm{~mm}$ using a displacement rate of $5 \mathrm{~mm} / \mathrm{min}$.

\section{Composite mechanical properties}

After demolding, the specimens were left under normal condition (temperature $(\mathrm{T})=20 \pm 2^{\circ} \mathrm{C}$ and relative humidity $(\mathrm{RH})=65 \pm 5 \%)$ until the date of the test in the laboratory.

For mechanical tests, standard specimens with size $4 \times 4 \times 16 \mathrm{~cm}^{3}$ are prepared for control mortar without fiber and gypsum mortars reinforced with raw or treated fibers.

The mechanical properties of composites were determined using an LLYOD machine test of capacity $20 \mathrm{KN}$.

Flexural strength. For the flexural test, three-point bending test has been used with a deflection rate of $0.1 \mathrm{~mm} / \mathrm{s}$ and a distance between supports of $10 \mathrm{~cm}$. The flexural strength is calculated according to the NF EN 12390-3 standard. $^{35}$

Compressive strength. The compressive test is determined with a deflection rate of $0.02 \mathrm{~mm} / \mathrm{s}$ on half of the specimens retained from the flexural test.

Thermal conductivity. All thermo-physical tests of composites were performed using samples with dimensions of $40 \times 20 \times 10 \mathrm{~mm}^{3}$.

The thermal conductivity and diffusivity were determined using the Hot disk method TPS $2500 \mathrm{~S}$ with a precision of $5 \%$ under the following climatic conditions: $\mathrm{T}=21^{\circ} \mathrm{C} \pm 2{ }^{\circ} \mathrm{C}$ and $\mathrm{RH}=45 \% \pm 10 \%$. 
The hot disk technique is used for a transient measurement of thermal conductivity and thermal diffusivity. It consists in fitting the sensor between the two pieces of the sample, each one with a plane surface.The sensor used in this test method is made of nickel foil which is wound in a double spiral pattern with a 6.403 radius.

For all specimens, each measurement is relative to three similar tests.

In order to estimate the potential of composite for building, the thermal diffusivity $\alpha$ is calculated using the following equation (equation (3))

$$
\alpha=\frac{\lambda}{\rho c}
$$

where $\lambda$ is the conductivity ( $\mathrm{W} / \mathrm{m} \mathrm{K}), \rho$ is the density $\left(\mathrm{kg} / \mathrm{m}^{3}\right)$ and $c$ is the specific heat $(\mathrm{J} / \mathrm{kg} \mathrm{K})$

\section{Results and discussions}

\section{Physical and morphological properties}

Physical properties. The physical properties for raw and treated fibers are listed in Table 6. These results indicated that the fiber diameter decreased with the alkali treatment because the treatment eliminated lignin and hemicellulose compounds (Figure 3).

Table 6 shows that the mechanically extracted fibers have higher linear density than the treated fiber because they contain residues of gummy material. So the chemical treatment improves fiber finesse.

The unit of the linear density is Tex, and it is a unit of measure for the linear mass density of fibers and referring to the mass in grams per $1000 \mathrm{~m}$ of a single filament

The mechanical characteristics of natural fibers are mainly influenced by their moisture content. As seen in Table 6, the treatment reduces the moisture content of doum palm fibers, which will increase their mechanical properties.

FTIR spectroscopy. To confirm our hypotheses about the treatments impacts on the fiber surfaces, we have proceeded to FTIR spectroscopy tests. FTIR analysis showed that the alkali treatment has modified the chemical composition of the fiber. FTIR spectra of raw and treated fibers are presented in Figure 4. A zoom was made in the range between 400 and $4000 \mathrm{~cm}^{-1}$ in order to focus on the region to analyze. ${ }^{39}$ In the spectrum of the raw doum fiber, the signal of their primary components (cellulose,hemicellulose and lignin) is clear as declared in the literature intensely. ${ }^{40}$ We observe a large band in the range of 3700$3353 \mathrm{~cm}^{-1}$ attributed to the hydrogen bond $-\mathrm{OH}$ of the cellulose. ${ }^{41}$ This band is more pronounced for treated fibers compared to raw fibers. The second band between 2800 and $3000 \mathrm{~cm}^{-1}$ consists of $\mathrm{C}-\mathrm{H}$ and $\mathrm{C}-\mathrm{H}_{2}$ bond characteristic of polysaccharides and

Table 6. Physical properties of doum palm fiber.

\begin{tabular}{lllll}
\hline & Diameter $(\mu \mathrm{m})$ & Linear density $($ Tex $)$ & Moisture content $(\%)$ & Density $\left(\mathrm{g} / \mathrm{cm}^{3}\right)$ \\
\hline Untreated fiber & $353.37 \pm 31.49$ & $71.63 \pm 18.37$ & $17.61 \pm 3.84$ & 1.32 \\
Treated fiber & $225.13 \pm 78.74$ & $66.59 \pm 11.96$ & $12.17 \pm 2.23$ & 1.26 \\
\hline
\end{tabular}
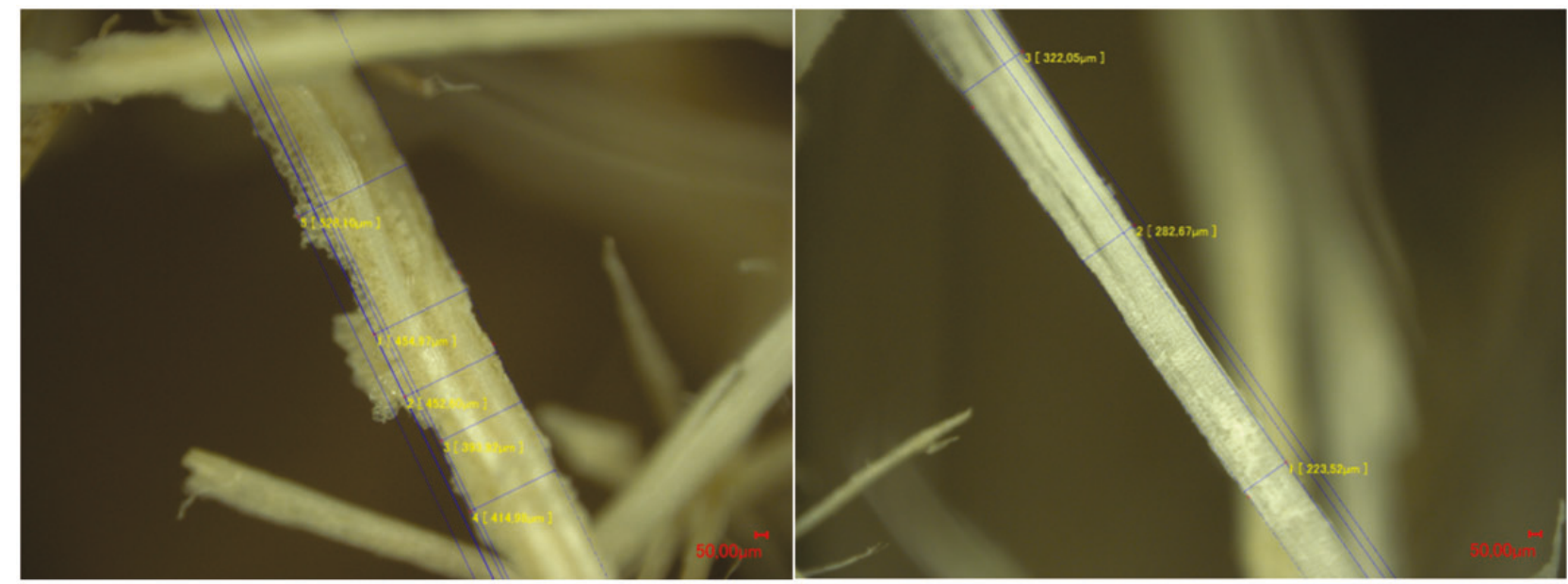

Figure 3. Digital microscope of doum fiber. 


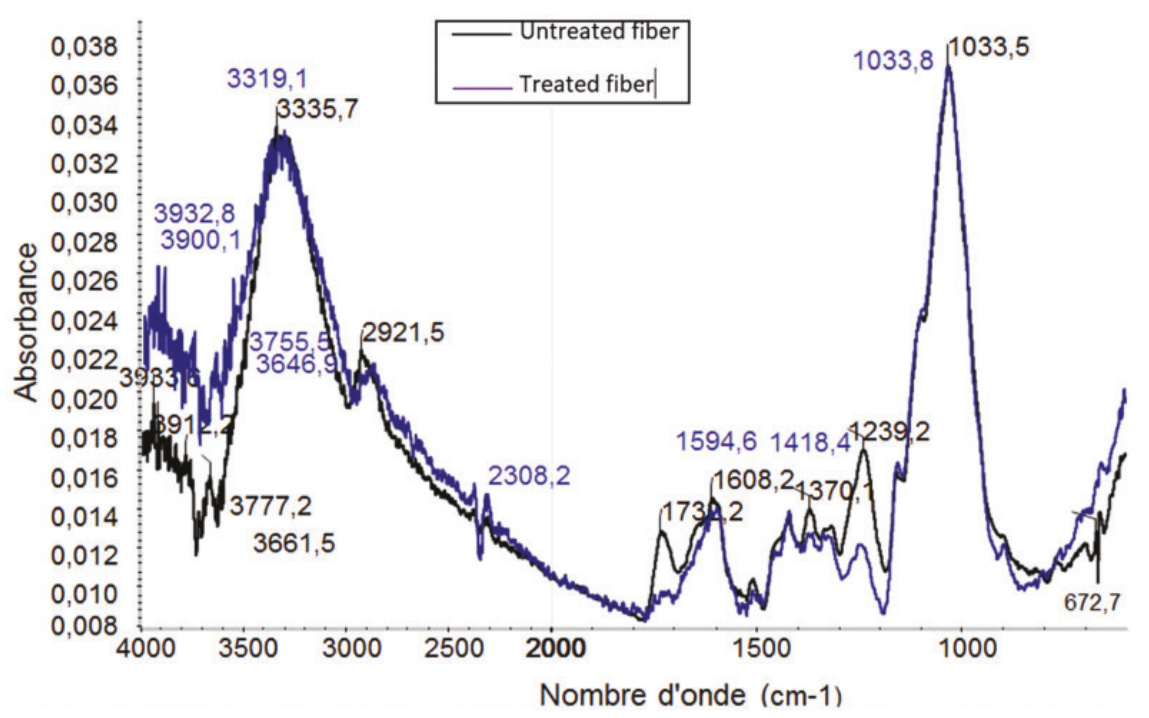

Figure 4. FTIR analysis.

greases. ${ }^{42}$ Compared to raw fibers, the peak in this band is more pronounced for treated fibers. This confirms the effect of the hydroxide treatment which has partially reduced the presence of non-cellulosic polysaccharides. The band between 1700 and $1800 \mathrm{~cm}^{-1}$ corresponds to $\mathrm{C}=\mathrm{O}$ bond characteristic of hemicelluloses. In this band, the peak is almost nonexistent for treated doum palm fiber. This confirms that treatment has partially eliminated hemicelluloses. Indeed, hemicelluloses are responsible for the hydrophilic character of the fibers. ${ }^{43}$

The peak at $1370.1 \mathrm{~cm}^{-1}$ also disappeared; it corresponds to the $\mathrm{CH}_{2}$ stretching which is mostly observed in lignin composites. This suppression results in a higher availability of interface bonding between the fiber and matrix. ${ }^{44}$

Mechanical properties. The mechanical properties of doum palm fibers such as tensile strength, young's modulus and elongation are presented in Table 7.

The results show that alkalization improves the mechanical properties of doum fiber compared to raw fiber. The tensile strength of fracture raised from $155.88 \mathrm{MPa}$ to $179.92 \mathrm{MPa}$ and the elastic modulus increases from $6.29 \mathrm{MPa}$ to $7.71 \mathrm{MPa}$. In fact, the fibers were cleaned from the impurities and the fibrils arrangement was modified to enable them to support more charge. Moreover, the amorphous matter was removed and the lignin surrounding the fibers was reduced. This result agrees well with the reported results in literature, and the fiber treatment increases the mechanical properties. ${ }^{33,45,46}$

Morphological characterization of fibers. The morphology of the fibers is important because it provides
Table 7. Mechanical properties of doum palm fiber.

\begin{tabular}{llll}
\hline & $\begin{array}{l}\text { Tensile } \\
\text { strength } \\
(\mathrm{MPa})\end{array}$ & $\begin{array}{l}\text { Young's } \\
\text { modulus } \\
(\mathrm{GPa})\end{array}$ & $\begin{array}{l}\text { Elongation } \\
\text { at break (\%) }\end{array}$ \\
\hline Untreated fiber & $155.88 \pm 12.03$ & $6.29 \pm 1.25$ & $6.23 \pm 2.92$ \\
Treated fiber & $179.92 \pm 11.37$ & $7.71 \pm 0.94$ & $8.46 \pm 1.26$ \\
\hline
\end{tabular}

information on the interfacial adhesion between the fibers and the matrix. To characterize the morphology of doum palm fibers, a HITACHI TM3030 scanning electron microscope (SEM) and Keyence Digital Microscope VHX 2000 was used.

Figure 5 represents the longitudinal views of doum palm fibers. This figure shows that they have irregular shapes covered with a layer of gummy and waxy substances. Their structure is similar to natural composites.

The cellulose fibrils are held together by lignin and hemicellulose to form fibers. In the plant, the fibers are linked together by lignin which has a high solubility in the alkali environment of the matrix.

Figure 6 presents the SEM images of doum palm fibers before and after $\mathrm{NaOH}$ treatment. Raw doum palm fibers are presented in Figure 5. Its surface is irregular and has many impurities and lignin residual. These impurities decrease the tensile properties of doum palm fibers because they raise the diameter of the fiber without sustaining any tensile loads. Moreover, these impurities can cause an unstable adhesion between the fiber and the matrix and minimize the mechanical properties of the composites.

SEM micrographics show an improvement on fiber surface after alkali treatment. The use of alkali 
(a)

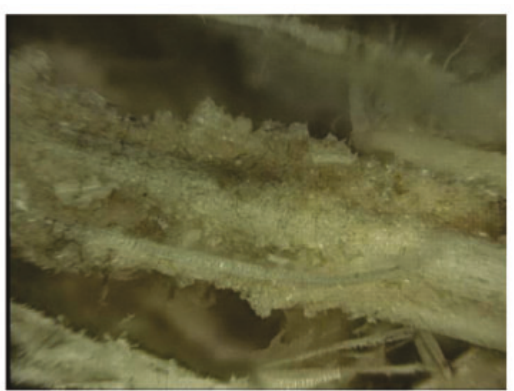

(c)

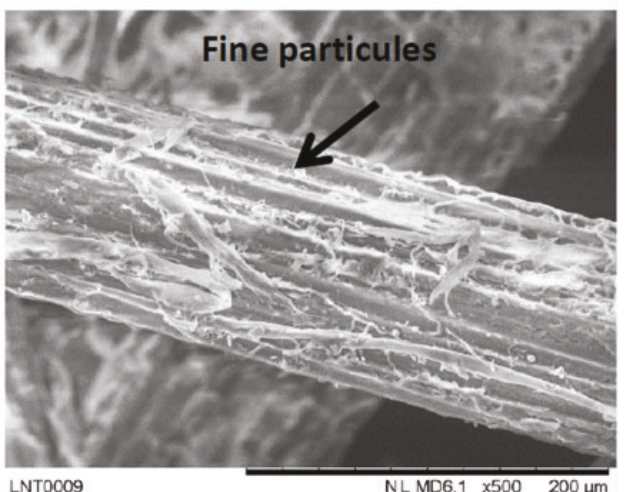

(b)

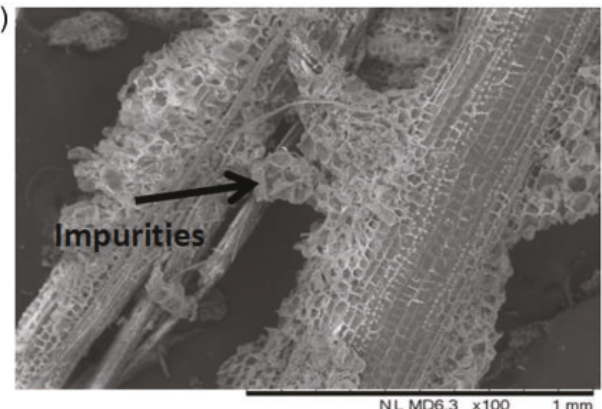

(d)

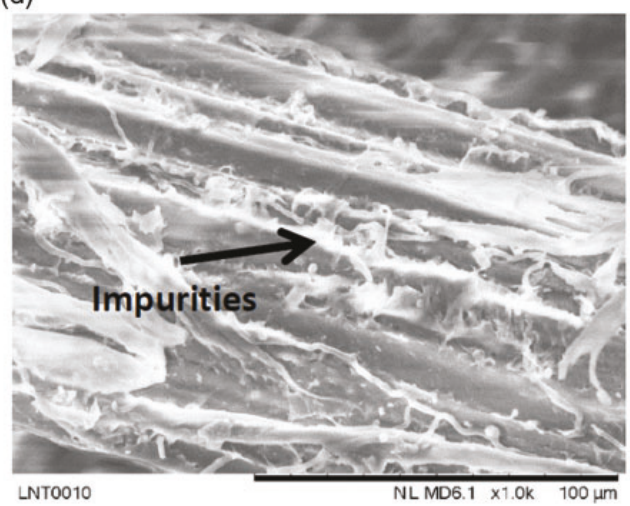

Figure 5. SEM and digital image of untreated doum palm fiber. With: (a) SEM image with magnification $\times 100$, (b) digital microscope image, (c) SEM image with magnification $\times 500$, (d)SEM image with magnification $\times 1000$.

(a)

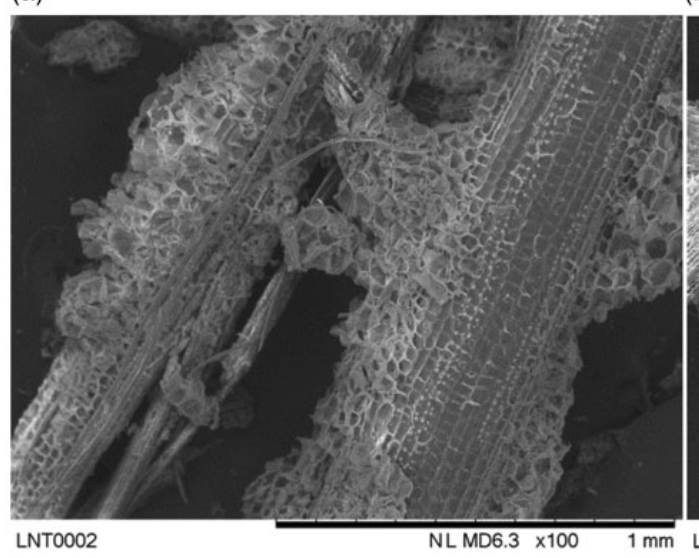

(b)

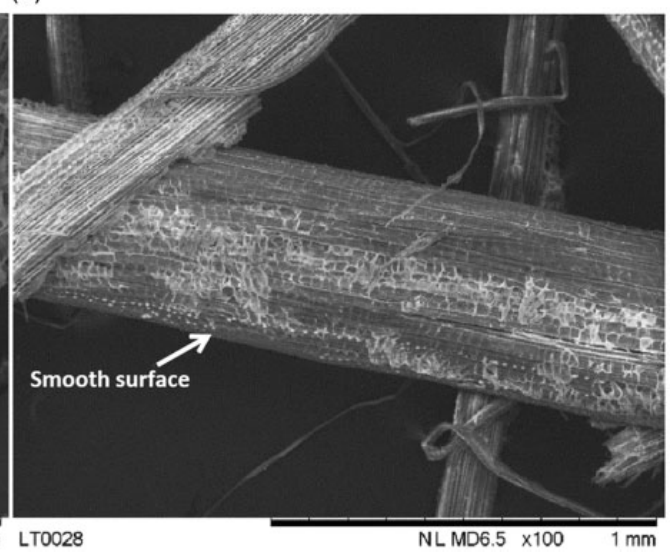

Figure 6. SEM image of doum palm fiber. With: (a) untreated fiber,(b) treated fiber.

treatment removed the impurities and the fatty substance from the surface of the fiber and this decreased the fiber diameter as indicated in Figure 6(b).

Rude palm fiber shows the existence of noncellulosic components on the surface of the fibers, and the alkaline treatment removes the impurities which contribute to a significant reduction of cementous material such as lignin and pectin.
For treated fiber, as it can be seen from (Figure 6(b)), the filament of fiber begins to degrade as a result of the degradation of the cellulose filaments. The oxygen begins to react with cellulose, thus resulting in the rupture of the cellulose chain due to the attack of the $\mathrm{C}-\mathrm{C}$ bonds. The alkali treatment removed some lignin and hemicellulose and allowed the fibrils to rearrange themselves in the traction direction, which led to 


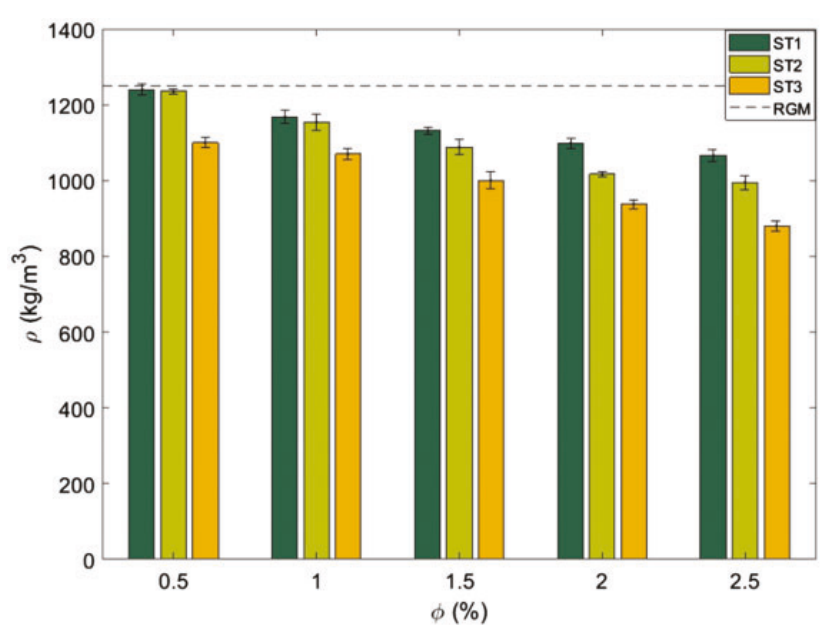

Figure 7. Density vs. fiber ratio.

a better packing of cellulose chains and a better sharing of the load.The surface becomes more porous and containing more voids.

Before treatment, the surface contained gummy and waxy substances as shown in Figure 6(a). This component facilitates the extraction of fibers from the matrix but after treatment (Figure 6(b)), the surface became much smoother without attacking cellulose microfibrils, which improved the adhesion between the fibers and the gypsum matrix. ${ }^{33}$

\section{Composites mechanical properties}

Effect of fiber mass fraction on the composite density. The density of specimens is an important property because it is on correlation with thermal characteristics. Figure 7 shows the effect of fiber content on composite density. As expected when increasing the fiber content and the size of fiber, a reduction in the composite density was observed. The reduction of density was more pronounced for specimen reinforced with RS3 accompanied by a decline of $12 \%$ in density compared to the reference gypsum.

Compressive behavior of reinforced gypsum mortar. Compressive strength is one of the most important properties of building materials.

Results show that the compressive strength decreased with the addition of untreated doum palm fiber to the mortar Figure 8(a). This result is expected and in agreement with previous findings. The incorporation of untreated fibers into the gypsum mortar caused a reduction in the compressive strength by $47 \%$ for SNT1, $62 \%$ for SNT2 and $72.33 \%$ for SNT3 for the value of $0.5 \%$ as seen in Figure 8(a).

As depicted in Figure 8(b), increasing the fiber percentage in the range of $1 \%$ to $2.5 \%$ for ST 1 and ST2
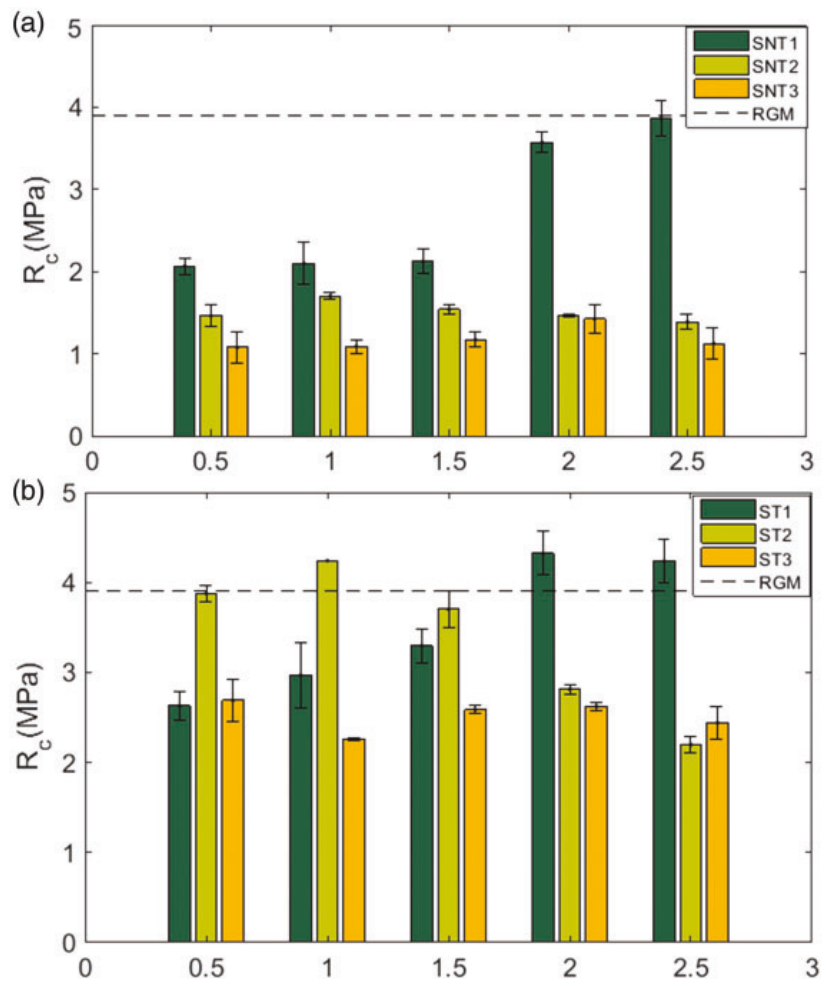

Figure 8. Compressive strength of gypsum mortar.

composites decreases the density which results in a decrease of the compressive strength and by consequence the capacity to resist to compression. Based on these results, we can conclude that the composite ST1 with $2 \%$ mass ratio represents the most important value of compressive strength.

The compressive strength increased with the increase of the used fibers content until an optimum value. This decrease beyond the optimum value is due to the packing of fibers, which became difficult at high fibers content and introduced many voids into the composite (Figure 8).

For ST1, the compressive strength grows with the increase of fiber ratio but until the value of $2 \%$, the gypsum mortar becomes unhandy. For the other mortar, the compressive strength increases until the value of $1 \%$ for ST2, and then it decreases. This is owing to a weak maneuverability due to the excess of fiber in the matrix and the increase of porosity.

According to Figure 8 for the same fiber ratio, the highest compressive strength is obtained for gypsum mortar reinforced with treated reinforcement seive2 (ST2) for the value of $1 \%$ fibers. We can also note that the addition of fibers perturbs the mineral skeleton of the gypsum mortar. It increases its porosity by creating voids inside the matrix.

After one year, the compressive strength of gypsum mortar reinforced with untreated reinforcement sieve 2 

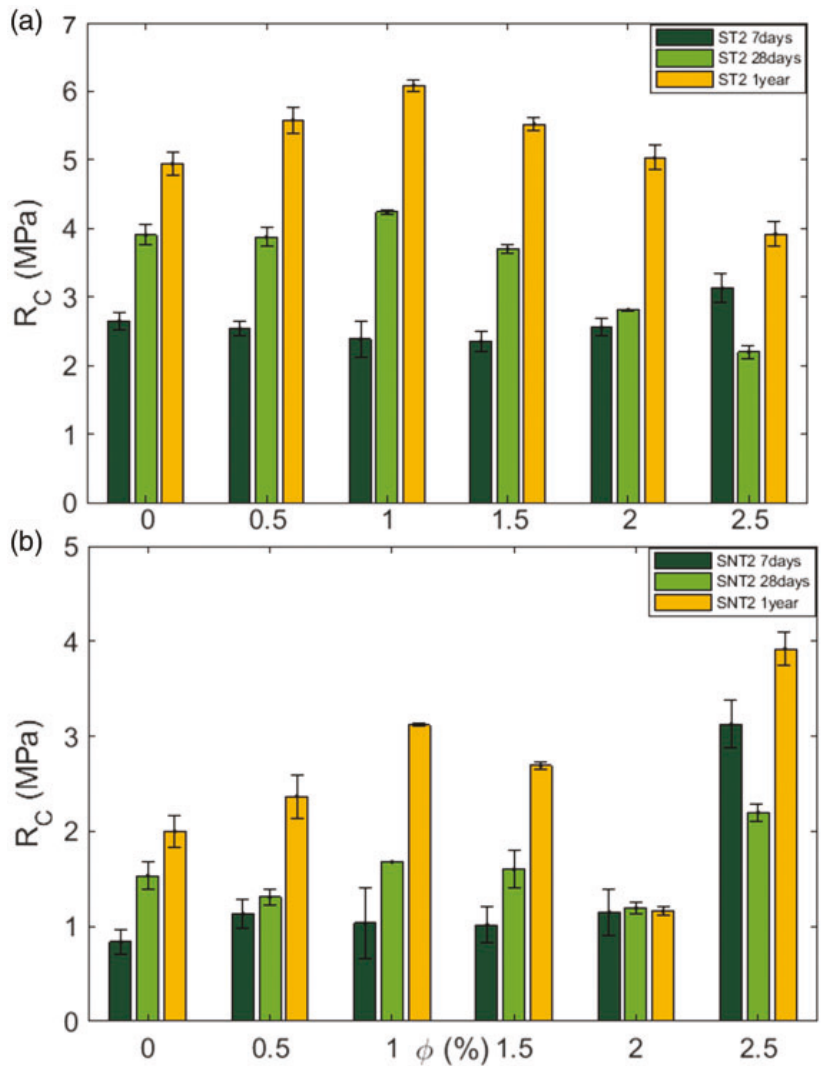

Figure 9. Effect of the aging time on the compressive strength.
(SNT2) decreased by $46 \%$ for the fiber ratio $2.5 \%$, and (Figure 9) this decrease can be related to the debonding of the fiber due to the alkaline attack and the weak fibermatrix adhesion. Besides, during mixing, untreated fibers absorbed a larger amount of water than treated fibers. This behavior causes weakening in the fiber and a decrease in its mechanical properties.

As for gypsum mortar reinforced with $1 \%$ of treated reinforcement sieve 2 (ST2), the compressive strength increased by $23 \%$ compared to the reference gypsum mortar (RGM). This behavior can be explained by the fact that the chemical treatment ameliorates the fibermatrix adhesion and removes compounds that are sensitive to water intake and to alkaline attacks such as hemicellulose, lignin, and pectin.

For the other composites, the compressive strength results are listed in Tables 8 and 9 .

For further increasing the fibers content, the compressive strength was decreased for the different types of fibers. This could be explained by the incorporation of doum palm fiber which reduces the density of fiber.

Flexural behavior of reinforced gypsum mortar. Figure 10 represents the flexural strength executed on $4 \times 4 \times 16 \mathrm{~cm}^{3}$ gypsum mortar samples. As it can be seen, adding untreated doum palm fiber causes a

Table 8. Compressive strength of STI and SNT I gypsum mortar.

\begin{tabular}{|c|c|c|c|c|c|c|}
\hline \multirow[b]{2}{*}{ Fiber ratio $(\%)$} & \multicolumn{3}{|c|}{ Compressive strength of SNTI (MPa) } & \multicolumn{3}{|c|}{ The compressive strength of STI ( $\mathrm{MPa})$} \\
\hline & 7 days & 28 days & I year & 7 days & 28 days & I year \\
\hline 0.5 & $2.47 \pm 0.45$ & $2.06 \pm 0.09$ & $4.95 \pm 0.08$ & $2.51 \pm 0.04$ & $2.63 \pm 0.15$ & $4.98 \pm 0.58$ \\
\hline I & $1.6 \mathrm{I} \pm 0.18$ & $2.10 \pm 0.36$ & $4.84 \pm 0.45$ & $2.60 \pm 0.15$ & $2.97 \pm 0.36$ & $5.83 \pm 0.36$ \\
\hline 1.5 & $1.18 \pm 0.12$ & $2.12 \pm 0.14$ & $3.69 \pm 0.79$ & $2.76 \pm 0.17$ & $3.29 \pm 0.58$ & $4.87 \pm 0.68$ \\
\hline 2 & $1.60 \pm 0.12$ & $3.57 \pm 0.36$ & $2.02 \pm 0.08$ & $3.22 \pm 0.09$ & $4.32 \pm 0.24$ & $4.90 \pm 0.20$ \\
\hline 2.5 & $\mathrm{I} .87 \pm 0.05$ & $3.86 \pm 0.44$ & $2.6 \mathrm{I} \pm 0.20$ & $3.37 \pm 0.23$ & $4.23 \pm 0.82$ & $4.62 \pm 0.45$ \\
\hline
\end{tabular}

Table 9. Compressive strength of SNT3 and ST3 gypsum mortar.

\begin{tabular}{|c|c|c|c|c|c|c|}
\hline \multirow{2}{*}{$\begin{array}{l}\text { Fiber } \\
\text { ratio (\%) }\end{array}$} & \multicolumn{3}{|c|}{ Compressive strength SNT3 (MPa) } & \multicolumn{3}{|c|}{ Compressive strength ST3 ( $\mathrm{MPa})$} \\
\hline & 7 days & 28 days & I year & 7 days & 28 days & I year \\
\hline 0.5 & $1.80 \pm 0.088$ & $1.07 \pm 0.184$ & $3,13 \pm 0.487$ & $2.17 \pm 0.151$ & $2.68 \pm 0.228$ & $5.22 \pm 0.214$ \\
\hline $\mathrm{I}$ & $1.07 \pm 0.193$ & $1.09 \pm 0.083$ & $2,31 \pm 0.32 I$ & $2.19 \pm 0.135$ & $2.26 \pm 0.014$ & $5.20 \pm 0.345$ \\
\hline 1.5 & $0.78 \pm 0.078$ & $\mathrm{I} .17 \pm 0.094$ & $2,18 \pm 0.178$ & $2.26 \pm 0.103$ & $2.58 \pm 0.043$ & $4.88 \pm 0.657$ \\
\hline 2 & $0.93 \pm 0.075$ & $1.42 \pm 0.179$ & $|, 4| \pm 0.23 \mathrm{I}$ & $2.27 \pm 0.214$ & $2.62 \pm 0.041$ & $4.64 \pm 0.125$ \\
\hline 2.5 & $0.79 \pm 0.103$ & $1.12 \pm 0.183$ & $\mathrm{I}, 5 \mathrm{I} \pm 0.14 \mathrm{I}$ & $2.24 \pm 0.167$ & $2.44 \pm 0.181$ & $4.61 \pm 0.321$ \\
\hline
\end{tabular}


reduction in the flexural strength compared to the gypsum mortar.

Flexural behavior of the gypsum mortar reinforced with treated doum palm fiber has been illustrated in

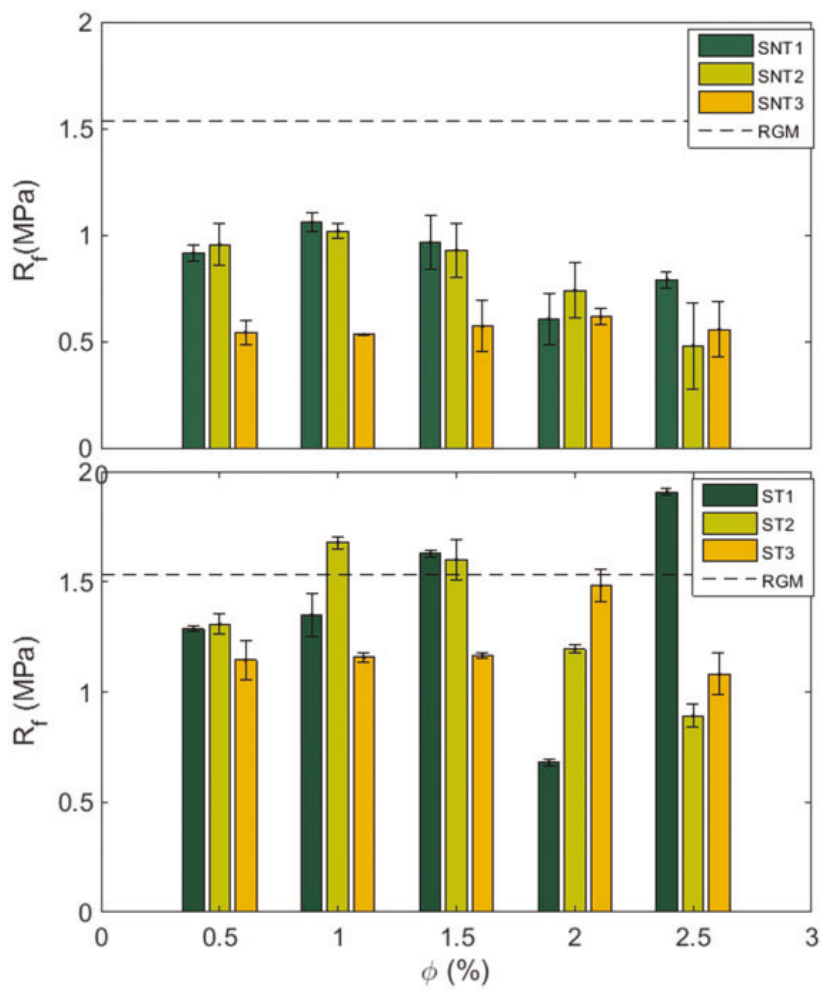

Figure 10. Flexural strength of gypsum mortar.
Figure 10. The composite reinforced with treated doum palm fiber underwent an important improvement for the flexural strength compared to the composite reinforced with raw fibers. This amelioration is attributed to a better adhesion between fiber and matrix. For ST2, an improvement of $28.4 \%$ is obtained for $1 \%$ fiber ratio.

The high mass ratio of the doum palm fiber leads to enhance the contacting surface area between the fiber and the matrix, and therefore the adhesion between the gypsum and fiber increases. Adding the important tensile strength of the fibers changes the mechanism of rupture. Instead of breaking, fiber pulled up from the matrix. This means that the flexural strength of composite was controlled by the bonding strength between the matrix and the fiber.

Increasing fiber content more than $1 \%$ creates disruption in the composite. Important quantities of doum palm fiber create a heterogeneous mixture with accumulated fiber.

Load/displacement curves of the different composite and the control mortar for $2 \%$ mass fraction are presented in Figure 11.

The reference gypsum mortar shows the typical catastrophic behavior of a brittle material, whereas the post-cracking behavior of the other composite was influenced by the addition of fiber.

Besides, the different type of fiber proved to be definitely effective in the gypsum mortar giving rise to a better post-cracking behavior.

By comparing ST3 curves to that of RGM, we note that the addition of ST3 fiber significantly modified the

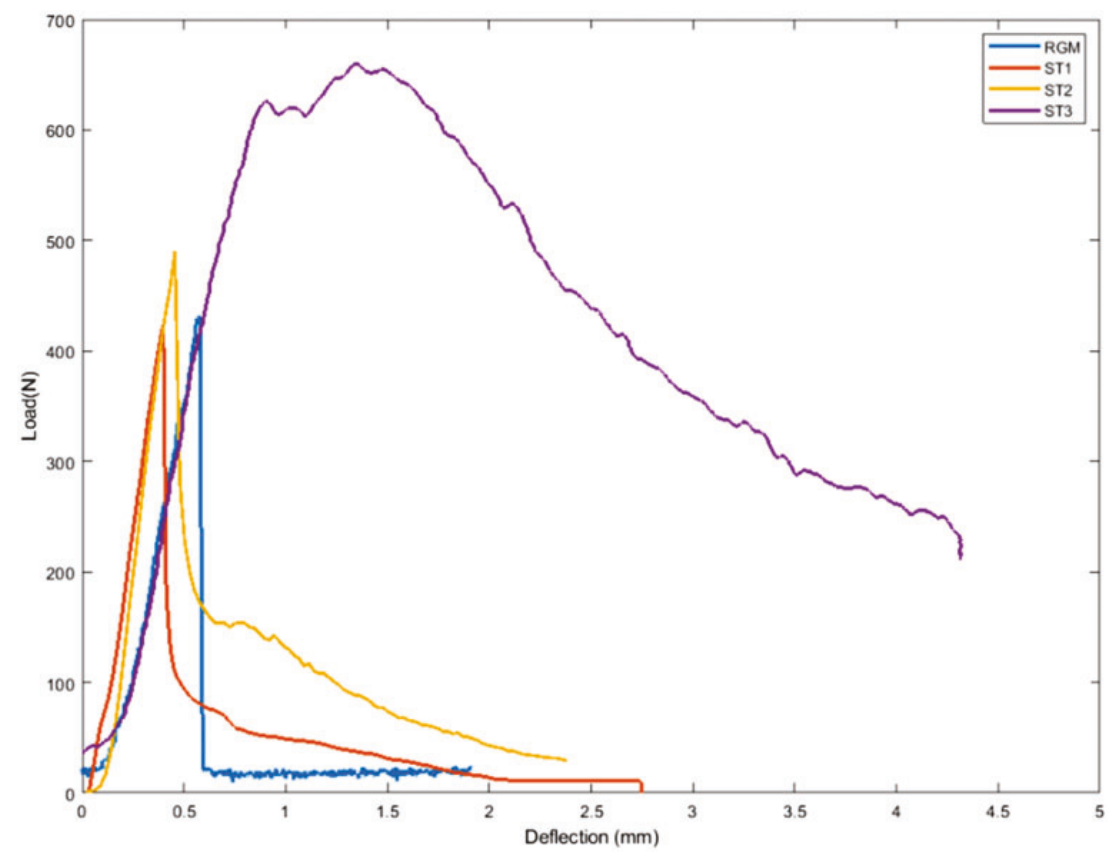

Figure II. Load-deflection curve of gypsum mortar. 
behavior of the gypsum mortar from a brittle to a more ductile one. From the figure, after the maximum flexural load, the defects propagation was reduced because the fibers reinforcement acts like bridges for the macrocrack.

For the specimen, ST1 and ST2 present the same failure; moreover, ST2 presents a greater post-cracking behavior compared with ST1 specimens with the highest load owed to the improvement of the load transfer between the fiber and matrix.

Figure 12 shows three-point bending tests results after 7 days, 28 days and 1 year to study the effect of
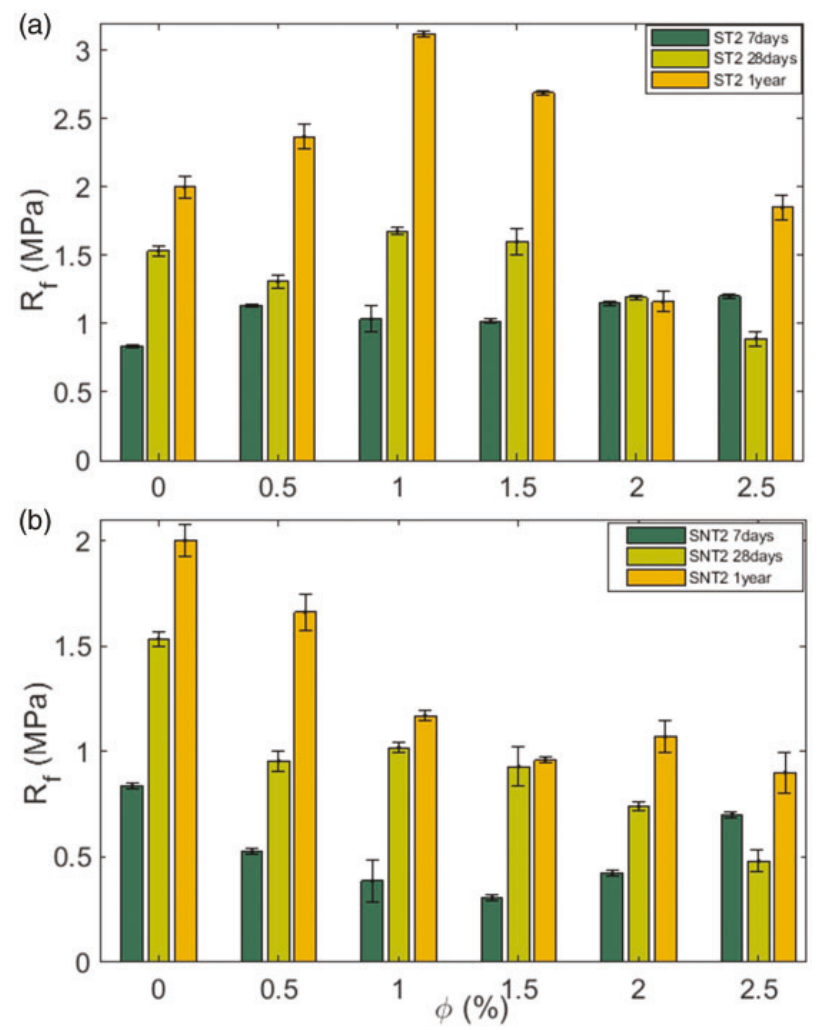

Figure 12. Effect on the aging time on the flexural strength. the aging time on the mechanical properties of reinforced gypsum mortar.

A significant decrease is noted for the composite reinforced with untreated fibers after 7 days, 28 days and 1 year. This could be explained by the fact that the fibers polymerization makes their surfaces smooth; hence, reduces their adhesion to the cement matrix.

However, Figure 12 demonstrates that for the case of ST2, the values of gypsum reinforced with treated doum palm fiber for the three curing times are higher than those of the reference gypsum mortar. The cracking of gypsum mortar arises in the fiber / mortar interface or as a propagation of default inside the matrix.The increase of the flexural strength demonstrate that fiber act as a bridge with the consequence of the reduction of defaults propagation.

For the other composites, the flexural strength results are listed in Tables 10 and 11. Almost similar results were obtained for the rest of the composites. The flexural strength increases by about $28 \%$ for ST1 and $12.5 \%$ for ST2 because the addition of doum palm fiber to the gypsum mortar causes a high porosity.

\section{Fiber-matrix interaction}

The interface between the matrix and the fibers plays an important role in determining the mechanical properties of composites. Good interfacial bonding is required to have a maximum reinforcement because the stress transferred between fiber and matrix passes through the interface.

Interfacial properties of doum palm-gypsum mortar composites are investigated by digital microscope Leica DMS300 and HITACHI TM3030 scanning electron microscopy (SEM).

Figure 13 presents the break surface of gypsum mortar reinforced with treated fiber. From Figure 14, it is clear that after bending test, fiber surface is covered by gypsum crystal which confirm the strong fiber/ matrix adhesion. It also shows an absence of globular porosity and cracking around fiber (Figure 13) due to

Table 10. Flexural strength of SNTI and STI gypsum mortar.

\begin{tabular}{|c|c|c|c|c|c|c|}
\hline \multirow{2}{*}{$\begin{array}{l}\text { Fiber } \\
\text { ratio (\%) }\end{array}$} & \multicolumn{3}{|c|}{ Flexural strength SNTI (MPa) } & \multicolumn{3}{|c|}{ Flexural strength STI(MPa) } \\
\hline & 7 days & 28 days & I year & 7 days & 28 days & I year \\
\hline 0 & $0.83 \pm 0.06$ & $1.53 \pm 0.03$ & $2 \pm 0.10$ & $0.83 \pm 0.06$ & $\mathrm{I} .53 \pm 0.12$ & $2 \pm 0.06$ \\
\hline 0.5 & $0.67 \pm 0.1$ & $0.91 \pm 0.07$ & $2.56 \pm 0.12$ & $\mathrm{I} .03 \pm 0.08$ & $1.28 \pm 0.18$ & $2.57 \pm 0.1$ \\
\hline 1 & $0.72 \pm 0.05$ & $1.60 \pm 0.03$ & $1.12 \pm 0.02$ & $1.04 \pm 0.18$ & $\mathrm{I} .34 \pm 0.26$ & $2.71 \pm 0.14$ \\
\hline 1.5 & $0.63 \pm 0.12$ & $1.05 \pm 0.12$ & $1.82 \pm 0.01$ & $1.06 \pm 0.12$ & $1.62 \pm 0.15$ & $2.52 \pm 0.06$ \\
\hline 2 & $0.42 \pm 0.12$ & $0.96 \pm 0.12$ & $1.03 \pm 0.05$ & $1.19 \pm 0.12$ & $1.68 \pm 0.16$ & $2.26 \pm 0.04$ \\
\hline 2.5 & $0.92 \pm 0.18$ & $1.79 \pm 0.04$ & $1.15 \pm 0.11$ & $1.36 \pm 0.05$ & $1.90 \pm 0.13$ & $2.16 \pm 0.13$ \\
\hline
\end{tabular}


Table II. Flexural strength of SNTI and STI gypsum mortar.

\begin{tabular}{|c|c|c|c|c|c|c|}
\hline \multirow[b]{2}{*}{ Fiber ratio (\%) } & \multicolumn{3}{|c|}{ Flexural strength of SNT3 $(\mathrm{MPa})$} & \multicolumn{3}{|c|}{ Flexural strength of ST3 (MPa) } \\
\hline & 7 days & 28 days & I year & 7 days & 28 days & I year \\
\hline 0 & $0.83 \pm 0.06$ & $1.53 \pm 0.03$ & $2 \pm 0.1$ & $0.83 \pm 0.06$ & $1.53 \pm 0.12$ & $2 \pm 0.06$ \\
\hline 0.5 & $0.50 \pm 0.08$ & $0.61 \pm 0.05$ & $2.25 \pm 0.13$ & $0.94 \pm 0.45$ & $1.14 \pm 0.09$ & $3.74 \pm 0.02$ \\
\hline 1 & $0.40 \pm 0.13$ & $0.54 \pm 0.18$ & $1.67 \pm 0.10$ & $0.91 \pm 0.18$ & $1.15 \pm .36$ & $2.9 \pm 0.23$ \\
\hline 1.5 & $0.39 \pm 0.07$ & $0.57 \pm 0.03$ & $\mathrm{I} .43 \pm 0.2 \mathrm{I}$ & $0.82 \pm 0.12$ & $1.16 \pm 0.14$ & $2.2 \pm 0.07$ \\
\hline 2 & $0.35 \pm 0.07$ & $0.53 \pm 0.13$ & $1.17 \pm 0.26$ & $0.73 \pm 0.12$ & $1.48 \pm 0.36$ & $2.36 \pm 0.20$ \\
\hline 2.5 & $0.37 \pm 0.1$ & $0.55 \pm 0.13$ & $I \pm 0.15$ & $\mathrm{I} .67 \pm 0.05$ & $1.08 \pm 0.44$ & $1.38 \pm 0.08$ \\
\hline
\end{tabular}

(a)

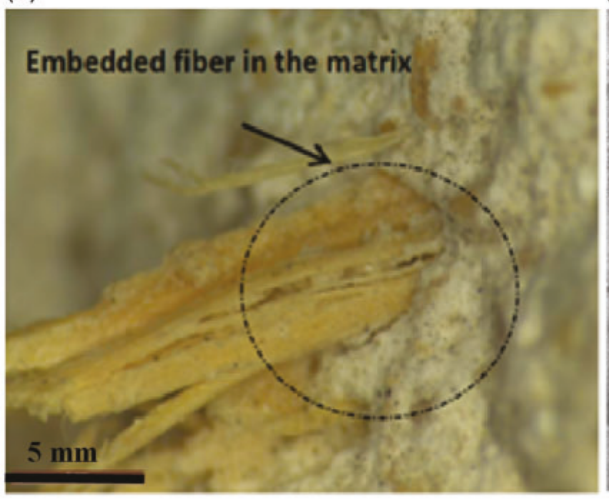

(b)

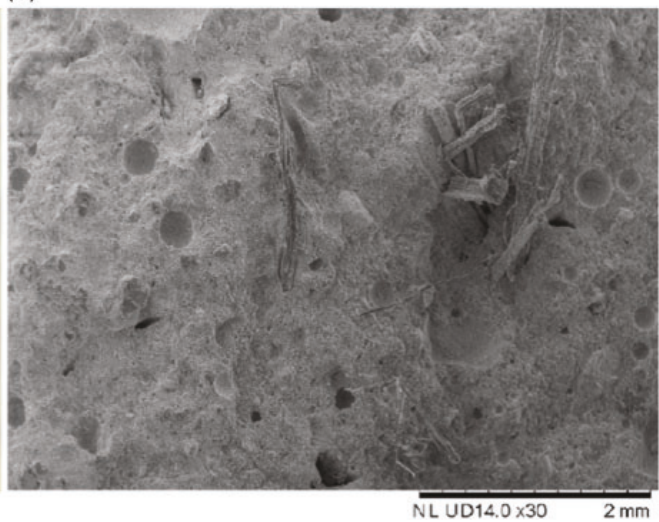

Figure 13. Composite reinforced with treated doum palm fiber. With: (a) digital image, (b) SEM image.

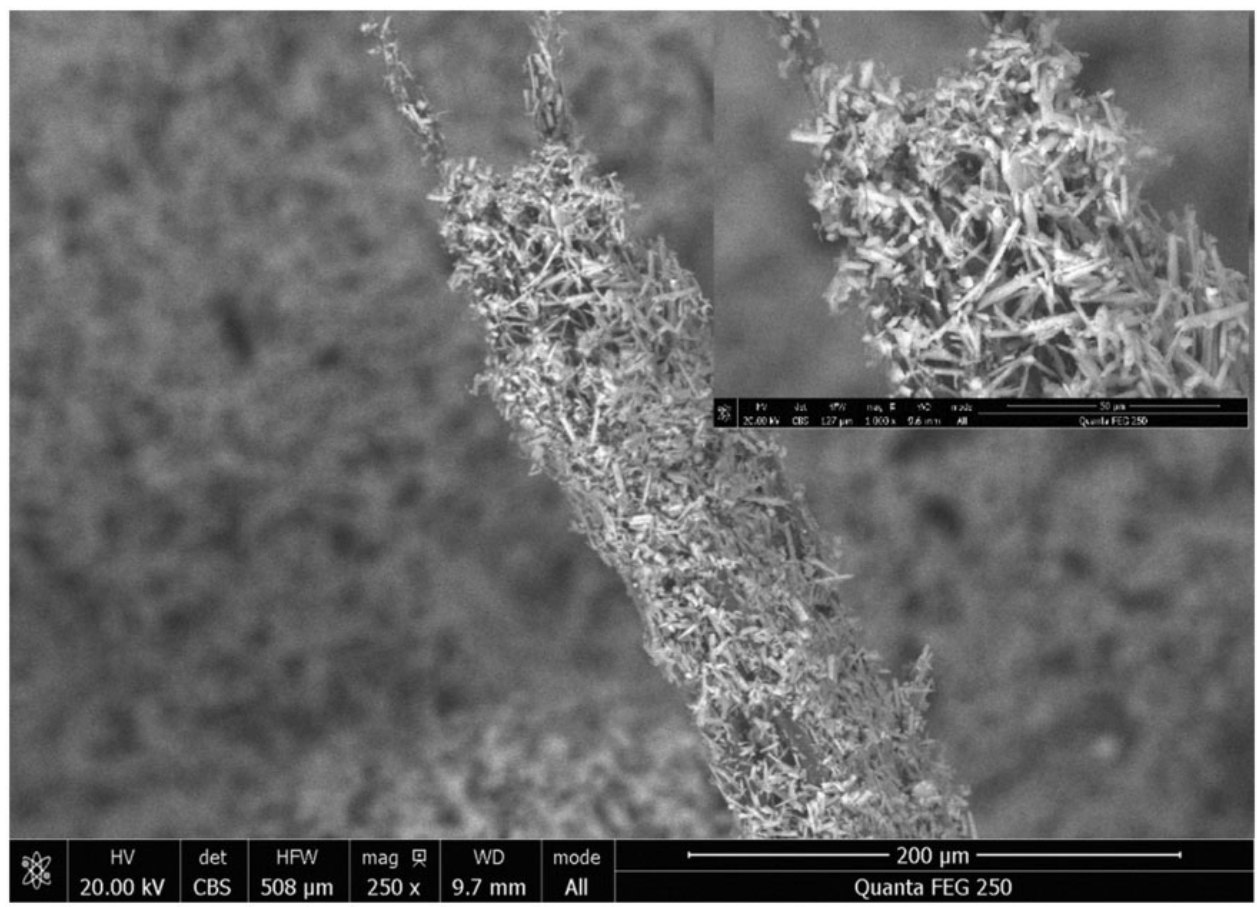

Figure 14. SEM image of treated fiber extracted from gypsum mortar. 
the strong adhesion between the fibers and the matrix without phase separation. This shows that the high toughness of this composite is due to the good interface between the fiber and matrix. It is also noticeable that fracture arises by a fiber pullout instead of a fiber breakdown. The alkali treatment induced a better adhesion between the fiber and matrix (Figure 13), ${ }^{47}$ while Figure 15 shows that the untreated fibers partly adhered with the matrix and pulled out from the matrix. After applying stress, several holes appeared due to the debonding of the fiber from the matrix, which indicates a weak adhesion between the fiber and the matrix. This behavior has contributed to lower mechanical properties. The fiber-matrix interface contains weak quantities of plaster grain in contact with the fiber. The surface of the pullout fiber from the matrix is smooth with no mark of adhesion.

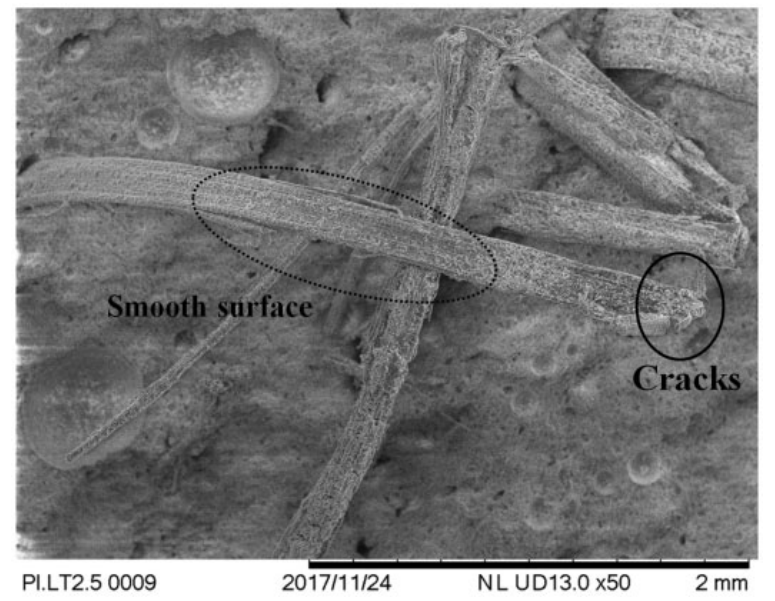

Figure I5. SEM image of composite reinforced with untreated doum palm fiber.

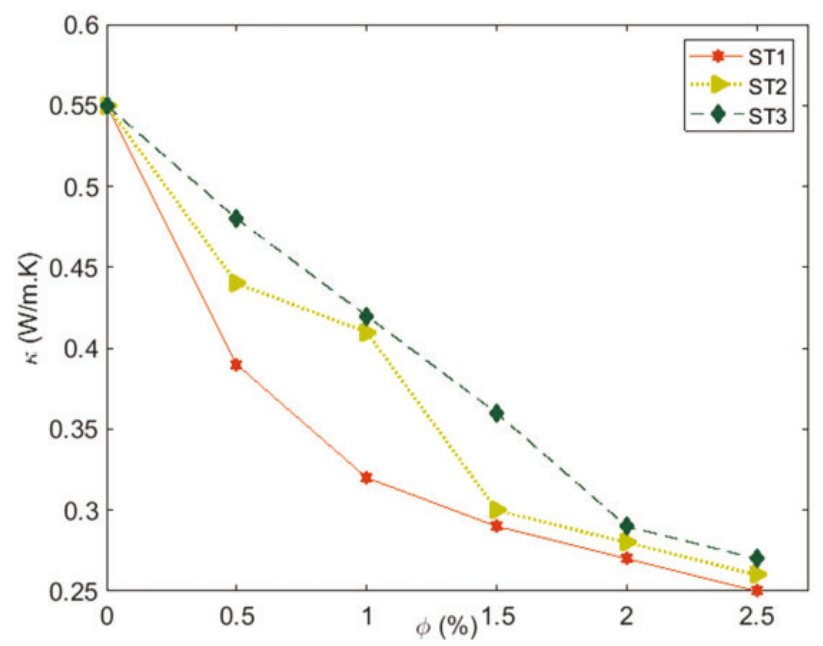

Figure 16. Thermal conductivity for different type of fibers.
However, this poor interaction between the fiber and the matrix leads to limit the interfacial bonding and gives low-mechanical properties.

\section{Thermo-physical properties by hot disk method}

Effect of mass fraction and fiber sizes. Figures 16 and 17 show the evolution of the thermal conductivity and the thermal diffusivity as a function of fibers content.

Figure 16 shows the results for the thermal conductivity for different composites compared with reference gypsum mortar. As can be seen, an increase of the ratio of doum palm fiber reduces the thermal conductivity of the specimen, consequently offering a new material with superior thermal behavior. Also, in the relation between the three types of fibers, the thermal conductivity for ST3 is higher than for the composites ST2 and ST1. The thermal conductivity of the material is regulated by the voids in the specimens. These voids appeared from packing fiber.

Commonly, the short fiber aligned well than the longer one. Thus, for a specific fiber content, mortar reinforced with longer fiber has a higher number of voids. This conducts to lower density and thermal conductivity.

Thereby, according to Figure 16, the thermal conductivity decreased by about $34.47 \%$ for ST1, $28.94 \%$ for ST2 and $39.28 \%$ for ST3. All presented values are the average of three samples.

Thermal diffusivity measures the rate of heat propagation through a material, and it is an important parameter to estimate their potential use in the building. Calculated thermal diffusivity values are presented in Figure 17. The addition of doum palm fiber decreases the thermal diffusivity of gypsum composites. The obtained results show an enhancement of the thermal

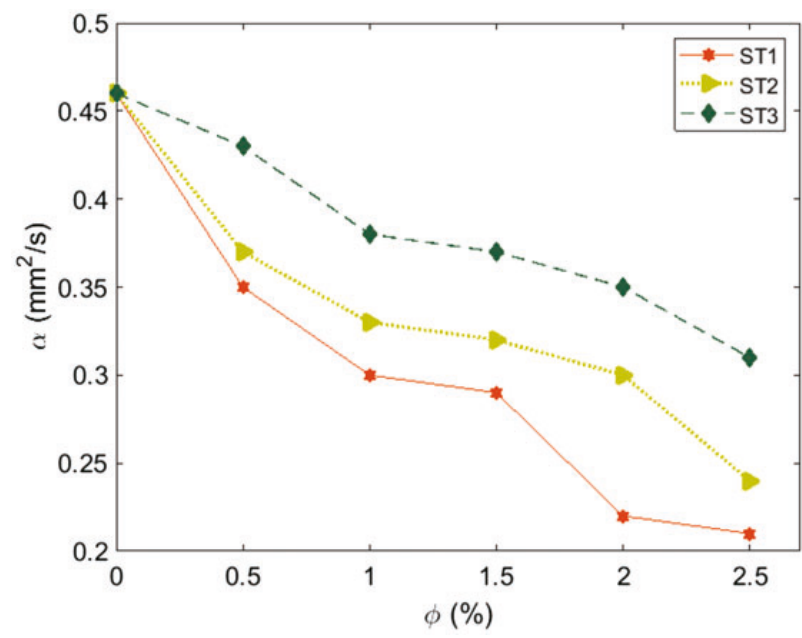

Figure 17. Thermal diffusivity for different type of fibers. 
Table 12. Thermal conductivity for a different type of composite.

\begin{tabular}{lllllll}
\hline \multirow{2}{*}{$\begin{array}{l}\text { Fiber } \\
\text { ratio (\%) }\end{array}$} & \multicolumn{7}{l}{ Thermal conductivity } & $\left(\mathrm{W} \mathrm{m}^{-1} \mathrm{k}^{-1}\right)$ & & \\
\cline { 2 - 7 } & $\mathrm{STI}$ & $\mathrm{SNTI}$ & $\mathrm{ST2}$ & $\mathrm{SNT2}$ & $\mathrm{ST3}$ & $\mathrm{SNT3}$ \\
\hline 0 & 0.55 & 0.55 & 0.55 & 0.55 & 0.55 & 0.55 \\
0.5 & 0.39 & 0.38 & 0.44 & 0.4 & 0.48 & 0.4 \\
$\mathrm{I}$ & 0.32 & 0.35 & 0.42 & 0.51 & 0.41 & 0.42 \\
1.5 & 0.31 & 0.35 & 0.36 & 0.41 & 0.29 & 0.34 \\
\hline
\end{tabular}

Table 13. Thermal diffusivity of different types of composite.

\begin{tabular}{|c|c|c|c|c|c|c|}
\hline \multirow{2}{*}{$\begin{array}{l}\text { Fiber } \\
\text { ratio (\%) }\end{array}$} & \multicolumn{6}{|c|}{ Thermal diffusivity $\left(\mathrm{mm}^{2} / \mathrm{s}\right)$} \\
\hline & STI & SNTI & ST2 & SNT2 & ST3 & SNT3 \\
\hline 0 & 0.46 & 0.46 & 0.46 & 0.46 & 0.46 & 0.46 \\
\hline 0.5 & 0.35 & 0.36 & 0.37 & 0.36 & 0.33 & 0.31 \\
\hline I & 0.30 & 0.25 & 0.35 & 0.43 & 0.24 & 0.33 \\
\hline 1.5 & 0.29 & 0.32 & 0.38 & 0.42 & 0.32 & 0.26 \\
\hline
\end{tabular}

Table 14. Most studies of thermo-physical properties for gypsum composite.

\begin{tabular}{llll}
\hline Materials & $\begin{array}{l}\text { Thermal conductivity } \\
(\mathrm{W} / \mathrm{m} \mathrm{K})\end{array}$ & $\begin{array}{l}\text { Energy } \\
\text { saving (\%) }\end{array}$ & References \\
\hline Reference gypsum mortar & 0.55 & - & This study \\
STI & 0.25 & 54.54 & This study \\
ST2 & 0.26 & 52.27 & This study \\
ST3 & 0.27 & 49.63 & This study \\
Wood shaving gypsum (40\%) & 0.2 & 18.8 & 48 \\
Wheat fiber/plaster (25\%) & 0.33 & 4.3 & 18 \\
Barley fiber/plaster (25\%) & 0.29 & 18.8 & 18 \\
Wood shaving gypsum (25\%) & 0.28 & 19.5 & 18 \\
\hline
\end{tabular}

diffusivity of the gypsum mortar by $54.34 \%, 47.82 \%$, and $21.39 \%$ for ST1, ST2 and ST3, respectively.

It is clear from Figure 17 that the addition of doum palm fiber has a positive influence on the heat diffusion amortization. Thus, the composite which contains high quantities of doum palm fiber, permits less heat diffusivity.

The effect of chemical treatment of doum palm fibers on the thermo-physical properties of the gypsum mortar is presented in Table 12.

The thermal conductivity of composites reinforced with untreated fibers is higher than that of composites reinforced with treated fibers. From Table 12, it is clear that the treatment decreases the thermal conductivity of the composites because it increases the fibers densities and consequently makes the composites more porous.
Table 13 presents the effect of chemical treatment on the thermal diffusivity of composites. Figure 6 shows that the treatment eliminates the impurities of fibers and increases their density, which makes the composite more porous with a low-thermal diffusivity.

A comparison between the composite used as insulation material and our composite were evaluated. Table 14 presents the comparison between thermal conductivity and diffusivity of some composites reinforced with other fibers. According to the table, we can report that the gypsum mortar in our work has a good thermal performance compared with another composite. Indeed, the thermal conductivity of ST2 is $0.26 \mathrm{~W} / \mathrm{m}$ $\mathrm{K}$, which means there is a decrease of $52.27 \%$ compared to the reference gypsum mortar. 
The energy saving is given by the following expres$\operatorname{sion}^{49}$ (equation (4))

$$
E_{S}=100 \times\left(1-\frac{\phi_{c}}{\phi_{g}}\right)
$$

We can suggest that using gypsum mortar reinforced with doum palm fiber is an alternative for thermal insulating material.

Effect of the density. Figure 18 represents the relationship between thermal conductivity and density for the different composites, and it is clear that thermal conductivity is proportional with density. This proves the direct relationship between the specimen's density and thermal conductivity. Increasing the quantity of fiber produces many voids leading to a low-thermal conductivity. This addictive (density/conductivity) is evident for the composite with mineral matrix and vegetable fiber according to Toledo et al. ${ }^{28}$ and Wei and Meyer. ${ }^{29}$

It is important to note that the lowest thermal conductivity was achieved for the composite reinforced with RS1.This can be attributed to the important quantities of a finer particle in RS1 than the other fibers, which were further resistant to the heat transfers.

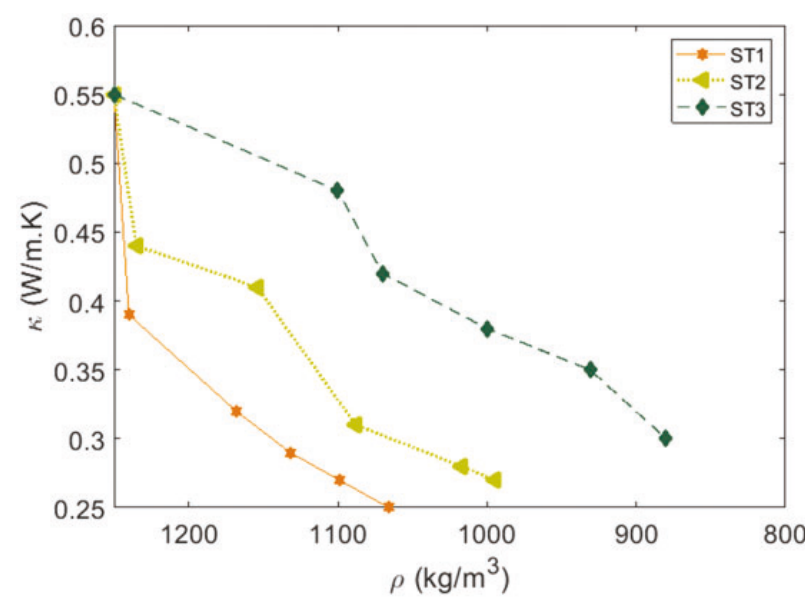

Figure 18. Thermal conductivity as a function of density.
Gypsum mortar with higher fiber content has lower thermal conductivity and superior thermal insulation capacity.

\section{Recapitulation}

Mechanical properties, thermal conductivity and density are decisive parameters for the determination of the optimal composition of the composite which satisfy the following specification according to the UNE EN $13272-1^{50-53}$ which are presented in Table 15.

Figure 19 describes the relationship $R_{c}=f(d)$; $\mathrm{k}=\mathrm{f}(\mathrm{d})$ for ST2 composite, and therefore this figure indicates that the thermal conductivity values drop by decreasing the density.

For compressive strength, it increases up to $1 \%$ fiber ratio, and beyond this fiber ratio, it decreases to $2.18 \mathrm{MPa}$.

The results obtained for the other composites are presented in Table 16. From the presented results in Tables 15 and 16, for RS2 fiber with a mass fraction of ratio $1 \%$, the mechanical properties are $4.2 \mathrm{MPa}$ for compressive strength, $3.11 \mathrm{MPa}$ for flexural strength, and thermal conductivity is $0.40 \mathrm{Wm}^{-1} \mathrm{~K}^{-1}$. These properties are similar with the lightweight gypsum.

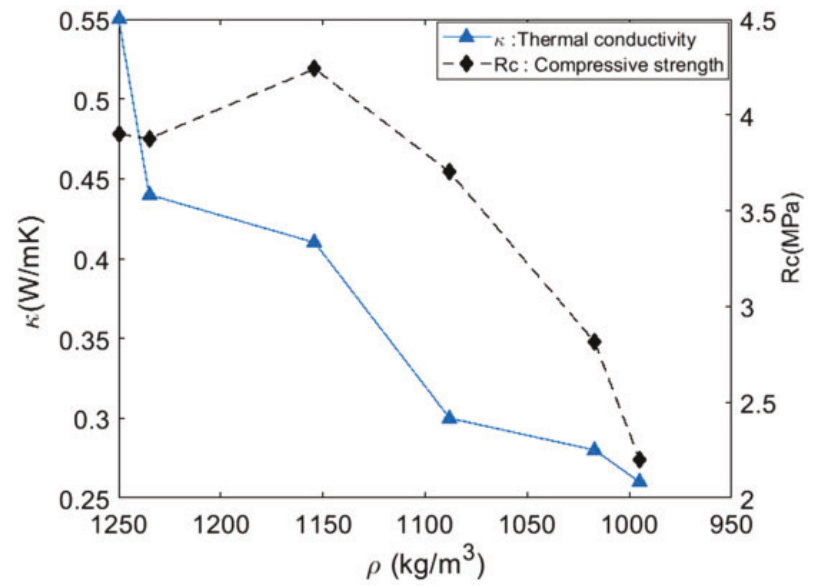

Figure 19. Compressive strength and thermal conductivity as a function of density.

Table 15. Functional classification for gypsum. ${ }^{50}$

\begin{tabular}{llllll}
\hline Gypsum & Code & $\begin{array}{l}\text { Density } \\
\left(\mathrm{kg} / \mathrm{m}^{3}\right)\end{array}$ & $\begin{array}{l}\text { Compressive } \\
\text { strength }(\mathrm{MPa})\end{array}$ & $\begin{array}{l}\text { Flexural } \\
\text { strength (MPa) }\end{array}$ & $\begin{array}{l}\text { Thermal } \\
\text { conductivity }\end{array}$ \\
\hline Gypsum & BI & & 4.6 & 6.4 & 0.52 \\
Gypsum mortar & B2 & 1680 & $\geq 2$ & $\geq 1$ & 0.4 \\
Lightweight gypsum & B4 & $\leq 1000$ & $\geq 2$ & $\geq 1$ & 0.4 \\
High hardness gypsum & B7 & & $\geq 6$ & $\geq 2$ & 0.5 \\
\hline
\end{tabular}


Table 16. Composites properties.

\begin{tabular}{llllllllll}
\hline & & STI & \multicolumn{3}{c}{ ST2 } & & \multicolumn{3}{c}{ ST3 } \\
\hline$\Phi(\%)$ & 0.5 & $\mathrm{I}$ & 1.5 & 0.5 & $\mathrm{I}$ & 1.5 & 0.5 & $\mathrm{I}$ & 1.5 \\
$\mathrm{R}_{\mathrm{c}}(\mathrm{MPa})$ & 2.63 & 2.9 & 3.29 & 3.8 & 4.2 & 3.75 & 2.68 & 2.26 & 2.58 \\
$\mathrm{R}_{\mathrm{f}}(\mathrm{MPa})$ & 1.28 & 1.34 & 1.62 & 2.4 & 3.11 & 2.65 & 1.14 & 1.15 & 1.16 \\
$\mathrm{~K}\left(\mathrm{Wm}^{-1} \mathrm{k}^{-1}\right)$ & 0.39 & 0.32 & 0.31 & 0.44 & 0.40 & 0.36 & 0.48 & 0.41 & 0.29 \\
$\rho\left(\mathrm{kg} / \mathrm{m}^{3}\right)$ & 1240 & 1168 & 1132 & 1235 & 1154 & 1088 & 1100 & 1070 & 1000 \\
\hline
\end{tabular}

Thus, as a conclusion, the optimum ratio of doum palm fiber is $1 \%$ for fiber ST2. Gypsum mortar filled with RS2 responds to the mechanical and thermal properties of construction materials.

The SEM image obtained from the surface fracture indicates that the surface of the treatment fiber is clearly very smooth. However, the surface of fiber after the fracture of specimens indicates the presence of plaster grain along the length of the fiber, which is coherent with the good adhesion between the fiber and the matrix, whereby this good adhesion between gypsum and fibers offers resistance to pull out and consequently enhances the plastic deformation.

\section{Conclusion}

In this work, an alkaline treatment of doum palm fiber has been implemented. Its effect on the behavior of a gypsum mortar composite and the properties of the fibers have been studied. The treatment improves the mechanical and physical properties of the fibers by partial removal of noncellulosic polysaccharide and important quantities of hemicellulose and lignin. FTIR spectroscopy tests have been applied on fibers; they confirm their surface modification due to the treatments.

On the other hand, the consequence of the chemical treatments on the mechanical behavior of the cement composite has been evaluated through the three-point bending tests. The $\mathrm{NaOH}$ treatment seems to ameliorate the fiber's surface roughness which results a better fiber matrix adhesion and composite with higher properties.

Moreover, an experimental evaluation of the fiber sizes and a mass fraction on the mechanical properties were investigated.

Flexural and compressive strength was reduced when adding a high fiber dosage (1.5\%) and a long fiber (RS2). This reduction is essentially reported firstly to the porosity provoked by a grouping of fiber and secondly the augmentation of tortuosity by increasing the fiber length.

Flexural toughness increases by the incorporation of doum palm fiber, and this augmentation was affected by the fiber dosage and the fiber length simultaneously.
Reference gypsum mortar has a brittle behavior under the flexural strength.

In this paper, the durability of gypsum mortar reinforced with doum fiber exposed to natural ageing was investigated. After one year of natural ageing, it was observed that the performance of the composite was improved at an average of $1.53 \mathrm{MPa}$ to $3.25 \mathrm{MPa}$ flexural strength.

Thus, this work has addressed to study the influence of fiber content and length on the thermal properties of gypsum mortar. The results indicate that the thermal conductivity is related to the fiber content. Accordingly, the thermal conductivity decreases by increasing the fiber content.

In conclusion, the results obtained by the present study clearly indicate that the use of RS2 doum palm fiber with $1 \%$ mass fraction is an attractive way to produce a biocomposite gypsum mortar.

\section{Declaration of Conflicting Interests}

The author(s) declared no potential conflicts of interest with respect to the research, authorship, and/or publication of this article.

\section{Funding}

The author(s) received no financial support for the research, authorship, and/or publication of this article

\section{ORCID iD}

Naiiri Fatma (D) http://orcid.org/0000-0003-3378-8933

\section{References}

1. Arikan M and Sobolev K. The optimization of a gypsumbased composite material. Cem Concr Res 2002; 32: $1725-1728$.

2. Garg M and Pundir A. Investigation of properties of fluorogypsum-slag composite binders - hydration, strength and microstructure. CemConcr Compos 2014; 5: 227-233.

3. Skujans J, Vulans A, Iljins U, et al. Measurements of heat transfer of multi-layered wall construction with foam gypsum. Appl Therm Eng 2007; 27: 1219-1224.

4. Vasconcelos G, Lourenço PB, Camões A, et al. Evaluation of the performance of recycled textile fibres in the mechanical behaviour of a gypsum and cork composite material. Cem Concr Compos 2015; 58: 29-39. 
5. Sawsen C, Fouzia K, Mohamed B, et al. Effect of flax fibers treatments on the rheological and the mechanical behavior of a cement composite. Constr Build Mater 2015; 79: 229-235.

6. Toubal L, Zitoune R, Collombet F, et al. Moisture effects on the material properties of a jute/epoxy laminate: impulse excitation technique contribution. J Nat Fibers 2018; 15: 39-52.

7. El Sawi I, Bougherara H, Zitoune R, et al. Influence of the manufacturing process on the mechanical properties of flax / epoxy influence of the manufacturing process on the mechanical properties of flax / epoxy composites. J Biobased Mater Bioenergy 2014; 8: 69-76.

8. Dicker MPM, Duckworth PF, Baker ABG, et al. Green composites: a review of material attributes and complementary applications. Compos Part A Appl Sci Manuf 2014; 56: 280-289.

9. Hamzaoui R, Guessasma S, Mecheri B, et al. Microstructure and mechanical performance of modified mortar using hemp fibres and carbon nanotubes. Mater Des 2014; 56: 60-68.

10. Dalmay P, Smith A, Chotard T, et al. Properties of cellulosic fibre reinforced plaster: influence of hemp or flax fibres on the properties of set gypsum. J Mater Sci 2010; 45: 793-803.

11. Malenab R, Ngo J and Promentilla M. Chemical treatment of waste abaca for natural fiber-reinforced geopolymer composite. Materials 2017; 10: 579.

12. Sghaier S, Zbidi F and Zidi M. Characterization of doum palm fibers after chemical treatment abstract 2009; 79: 1108-1114.

13. Kriker A, Bali A, Debicki G, et al. Durability of date palm fibres and their use as reinforcement in hot dry climates. Cem Concr Compos 2008; 30: 639-648.

14. Magniont C, Escadeillas G, Coutand M, et al. Use of plant aggregates in building ecomaterials. Euro $J$ Environ Civil Eng 2012; 16: 17-33.

15. Van de Weyenberg I, Chi Truong T, Vangrimde B, et al. Improving the properties of UD flax fibre reinforced composites by applying an alkaline fibre treatment. Compos Part A Appl Sci Manuf 2006; 37: 13682006.

16. Benmansour N, Agoudjil B, Gherabli AA, et al. Thermal and mechanical performance of natural mortar reinforced with date palm fibers for use as insulating materials in building. Energy Build 2014; 81: 98-104.

17. Monties B. Plant cell walls as fibrous lignocellulosic composites: relations with lignin structure and function. Anim Feed Sci Technol 1991; 32: 159-175.

18. Ashour T, Wieland $\mathrm{H}$, Georg $\mathrm{H}$, et al. The influence of natural reinforcement fibres on insulation values of earth plaster for straw bale buildings. Mater Des 2010; 31: 4676-4685.

19. Mangal R, Saxena NS, Sreekala MS, et al. Thermal properties of pineapple leaf fiber reinforced composites. Mater Sci Eng A 2003; 339: 281-285.

20. Palumbo M, McGregor F, Heath A, et al. The influence of two crop by-products on the hygrothermal properties of earth plasters. Build Environ 2016; 105: 245-252.
21. Asasutjarit C, Hirunlabh J, Khedari J, et al. Development of coconut coir-based lightweight cement board. Constr Build Mater 2007; 21: 277-288.

22. Djoudi A, Khenfer MM, Bali A, et al. Effect of the addition of date palm fibers on thermal properties of plaster concrete: experimental study and modeling. J Adhes Sci Technol 2014; 28: 2100-2111.

23. Chung DDL. Cement-matrix composites for thermal engineering. Appl Therm Eng 2001; 21: 1607-1619.

24. Mazhoud B, Collet F, Pretot S, et al. Hygric and thermal properties of hemp-lime plasters. Build Environ 2016; 96: 206-216.

25. Kim S, et al. Physico-mechanical properties and the TVOC emission factor of gypsum particleboards manufactured with Pinus massoniana and Eucalyptus sp. Macromol Mater Eng 2007; 292: 1256-1262.

26. Ramli M, Kwan WH and Abas NF. Strength and durability of coconut-fiber-reinforced concrete in aggressive environments. Constr Build Mater 2013; 38: 554-566.

27. Politécnica E, Paulo UDS and Postal C. Materials durability evaluation of vegetable fibre reinforced materials. Build Res Inf 2007; 20: 233-235.

28. Toledo Filho RD, Silva F de A, Fairbairn EMR, et al. Durability of compression molded sisal fiber reinforced mortar laminates. Constr Build Mater 2009; 23: 2409-2420.

29. Wei J and Meyer C. Degradation rate of natural fiber in cement composites exposed to various accelerated aging environment conditions. Corros Sci 2014; 88: 118-132.

30. Belayachi N, Hoxha D and Slaimia M. Impact of accelerated climatic aging on the behavior of gypsum plasterstraw material for building thermal insulation. Constr Build Mater 2016; 125: 912-918.

31. Ozerkan NG, Ahsan B, Mansour S, et al. Mechanical performance and durability of treated palm fiber reinforced mortars. Int J Sustain Built Environ 2013; 2: 131-142.

32. Taallah B, Guettala A, Guettala S, et al. Mechanical properties and hygroscopicity behavior of compressed earth block filled by date palm fibers. Constr Build Mater 2014; 59: 161-168.

33. Li X, Tabil LG and Panigrahi S. Chemical treatments of natural fiber for use in natural fiber-reinforced composites: a review. J Polym Environ vol 2007; 15: 25-33.

34. European Committee For Standardization, EN 132792:2014. Gypsum binders and gypsum plasters - Part 2: Test Methods., Eur Stand EN 13279-2, 2014, pp. 3-23.

35. ASTM. Standard test methods for physical testing of gypsum, gypsum plasters and gypsum. ASTM, vol. 99, no. Reapproved, pp. 1-8, 2015 .

36. Mokhtar R. Optimal composition of plaster mortar reinforced with palm fibers. J Civil Eng Environ Sci 2018; 4: 44-49.

37. ASTM D 157707 standard test methods for linear density of textile fibers, 2007.

38. International Organization for Standardization.TextilesFibres-Determination of breaking force and elongation at break of individual fibres- Part 2. Br Stand EN 5079-2, 1996, pp. 3-18. 
39. Yang H. Characteristics of hemicellulose, cellulose and lignin pyrolysis. Fuel 2007; 86: 1781-1788.

40. Yang H, Yan R, Chen H, et al. Mechanism of palm oil waste pyrolysis in a packed bed. Energy Fuels 2006; 20: 1321-1328.

41. Kokot S, Czarnik-matusewicz B and Ozaki Y. Two-dimensional correlation spectroscopy and principal component analysis studies of temperature-dependent ir spectra of cotton - cellulose. Biopolymers 2002; 67: 456-469.

42. Andreeva OA, Burkova LA, Grebenkin AN, et al. IR spectroscopic study of prepurified flax. Russian $J$ Appl Chem 2002; 75: 1513-1516.

43. He J, Tang Y and Wang S. Differences in morphological characteristics of bamboo fibres and other natural cellulose fibres: studies on X-ray diffraction, solid state 13C-CP/MAS NMR, and second derivative FTIR spectroscopy data. Iran Poym J 2007; 16: 807-818.

44. Hyness NRJ, Vignesh NJ, SenthamaraiKannan P, et al. Characterization of new natural cellulosic fiber from heteropogon contortus plant characterization of new natural cellulosic fiber from heteropogon. J Nat Fibers 2017; 15: $1-8$.

45. Ma Y, Liu Y, Ma S, et al. Friction and wear properties of dumbbell-shaped jute fiber-reinforced friction materials. J Appl Polym Sci 2014; 131: 2-9.

46. Carbonell-verdú A, Samper MD, Pop A, et al. Development and characterization of a new natural fi ber reinforced thermoplastic (NFRP) with Cortaderia selloana (Pampa grass) short fibers. Compos Sci Technol 2017; 145: 1-9.

47. Silva FJ and Thaumaturgo C. Fibre reinforcement and fracture response in geopolymeric mortars. Fatigue Fract Eng Mater Struct 2003; 26: 167-172.

48. Morales-Conde MJ, Rodríguez-Liñán $\mathrm{C}$ and PedreñoRojas MA. Physical and mechanical properties of wood-gypsum composites from demolition material in rehabilitation works. Constr Build Mater 2016; 114: 6-14.

49. Mounir S, Maaloufa Y, Cherki AB, et al. Thermal properties of the composite material clay/granular cork. Constr Build Mater 2014; 70: 183-190.

50. European Committee For Standardization. Gypsum binders and gypsum plasters Part 1: Definitions and requirements, Eur Stand EN 13279-1, 2008, pp. 3-20.

51. Zbidi F, Sghaier S, Nejma MB, et al. Influence of alkaline and enzymatic treatments on the properties of doum palm fibres and composite. J Appl Sci 2009; 9: 366-371.

52. Alawar A, Hamed AM and Al-Kaabi K. Characterization of treated date palm tree fiber as composite reinforcement. Compos Part B Eng 2009; 40: 601-606.

53. Sghaier S, Zbidi F and Zidi M. Characterization of doum palm fibers after chemical treatment. Text Res J 2009; 791: 1108-1114. 